\title{
Rochas dioríticas do Platô da Ramada, Rio Grande do Sul, e sua relação com o vulcanismo alcalino da Formação Acampamento Velho, Neoproterozoico do Escudo Sul-Rio-Grandense
}

\author{
Vinícius Matté ${ }^{1 *}$, Carlos Augusto Sommer², Evandro Fernandes de Lima', Dejanira Luderitz \\ Saldanha², Jussara Alves Pinheiro-Sommer ${ }^{3}$,Joaquim Daniel de Liz ${ }^{4}$
}

\begin{abstract}
Resumo Estudos realizados no Platô da Ramada (região Centro-Oeste do Rio Grande do Sul) permitiram a caracterização de um corpo hipabissal diorítico, intrusivo em rochas piroclásticas da Formação Acampamento Velho. Esta unidade é constituída por rochas vulcânicas de composição predominantemente ácida, com termos básicos associados, e corresponde à porção extrusiva do magmatismo alcalino sódico de idade Neoproterozoica (570-550 Ma), vinculado aos estágios pós-colisionais do Ciclo Brasiliano-Panafricano no Escudo Sul-Rio-Grandense. O corpo intrusivo varia desde termos dioríticos até quartzo-monzoníticos e sua afinidade alcalina sódica é atestada pelos padrões de elementos litófilos de grande raio iônico (LILE), elementos de elevado potencial iônico (HFSE) e elementos terras raras (ETR), cujas características indicam sua correlação com o magmatismo alto Ti da Formação Acampamento Velho, descrito no Platô da Ramada. A evolução do magmatismo alcalino da Formação Acampamento Velho nesta região pode ser explicada, principalmente, por processos de cristalização fracionada envolvendo três estágios principais, conforme resultados obtidos por meio de modelamentos petrogenéticos apresentados neste artigo. No entanto, face ao grande volume de rochas riolíticas de alta sílica e a complexidade que envolve a geração e a evolução destes líquidos, a possibilidade de que tenham ocorrido processos de cristalização fracionada associados possivelmente a mecanismos de assimilação crustal é grande. A identificação e a caracterização de rochas intermediárias relacionadas à Formação Acampamento Velho no Platô da Ramada indicam, portanto, que o magmatismo provavelmente evoluiu desde composições básicas até ácidas. Porém, a assertiva relacionada à bimodalidade do vulcanismo ainda permanece, devido à ausência de lavas andesíticas. Tal ausência pode ser atribuída a uma 'barreira de densidade' gerada pela diferenciação dos líquidos básicos para intermediários enriquecidos em $\mathrm{FeO}$, os quais, por esta razão, estacionariam nos níveis crustais rasos.
\end{abstract}

Palavras-chave: vulcanismo; magmatismo alcalino; intrusão diorítica; cristalização fracionada.

\begin{abstract}
Dioritic rocks of the Ramada Plateau, in Rio Grande do Sul State, and their relation to alkaline magmatism of Acampamento Velho Formation, Neoproterozoic of the Sul-Rio-Grandense Shield. Studies carried out in the Ramada Plateau (Western of the Rio Grande do Sul State, Brazil), have allowed the characterization of a dioritic hipabissal body, which is intrusive in pyroclastic rocks of the Acampamento Velho Formation. This unit consists of volcanic rocks of predominantly silicic composition in association with basic rocks, and it corresponds to the extrusive portion of the sodic alkaline magmatism of the Neoproterozoic age (570-550 Ma), related to postcollisional events of the Brasiliano-Pan Africano cycle of Sul-Rio-Grandense Shield. The intrusive body ranges from diorite to quartz-monzonite and its sodic alkaline affinity is attested by the large-ion lithophile elements (LILE), high-field strength elements (HFSE) and rare earth elements (REE) contents, whose characteristics indicate its correlation with the high Ti magmatism of Acampamento Velho Formation, described in the Ramada Plateau. The alkaline magmatism evolution of Acampamento Velho Formation in this region can be explained mainly by fractional crystallization processes, involving three main stages, according to petrogenetic models presented in this work. However, given the huge volume of high-silica rhyolitic rocks and the complexity involved in the generation and evolution of these magmas, probably crustal assimilation has occurred together with fractional crystallization processes. The identification and characterization of intermediate rocks related to Acampamento Velho Formation in Ramada Plateau thus indicate that the magmatism must have evolved from basic to acidic compositions. But, the premise of bimodal volcanism still remains due to the absence of andesitic lavas, which can be attributed to a 'density barrier' created by the differentiation of basic to intermediate liquids enriched in FeO. Therefore, such liquids were probably placed in shallow crustal levels.
\end{abstract}

Keywords: volcanism; alkaline magmatism; dioritic intrusion; fractional crystallization.

${ }^{1}$ Programa de Pós-graduação em Geociências, Instituto de Geociências, Universidade Federal do Rio Grande do Sul - UFRGS, Porto Alegre (RS), Brasil. E-mail: vinimatte@msn.com

2Instituto de Geociências, Universidade Federal do Rio Grande do Sul - UFRGS, Porto Alegre (RS), Brasil. E-mail: casommer@ sinos.net, evandro.lima@ufrgs.br, dejanira.saldanha@ufrgs.br

${ }^{3}$ Programa de Pós-Graduação em Geografia - PPGGEA, Universidade Federal do Rio Grande do Sul - UFRGS, Porto Alegre;

Universidade Luterana do Brasil - ULBRA, Canoas (RS), Brasil. E-mail: japsommer@sinos.net

${ }^{4}$ Rio Verde Minerals Ltda, Rio de Janeiro (RJ), Brasil. E-mail: deliz@rvminerals.com

*Autor correspondente 


\section{INTRODUÇÃOO O Platô da Ramada é uma} região caracterizada geologicamente pela expressiva ocorrência de depósitos vulcânicos efusivos e piroclásticos e intrusões subvulcânicas associadas, de composição dominantemente ácida e com termos básicos subordinados. Localiza-se a cerca de $20 \mathrm{~km}$ ao Sul do município de Vila Nova do Sul, na porção Centro-Oeste do estado do Rio Grande do Sul (Fig. 1), e constitui uma das melhores ocorrências da Formação Acampamento Velho. Corresponde à porção extrusiva do magmatismo alcalino sódico e saturado em sílica, de idade Neoproterozoica (570-550 Ma), vinculado aos estágios pós-colisionais do Ciclo Brasiliano-Panafricano no Escudo Sul-Rio-Grandense (Wildner et al. 2002, Sommer et al. 2005, 2006).

A Formação Acampamento Velho é constituída por rochas vulcânicas efusivas e explosivas e está inserida estratigraficamente no contexto geológico da Bacia do Camaquã. Os primeiros trabalhos nesta Formação datam do início dos anos 1940 (Leinz et al. 1941), nos quais foram descritos riolitos no, então chamado, "Planalto da Ramada". Desde então, inúmeros pesquisadores têm trabalhado nesta Formação, possibilitando a identificação e a individualização de diferentes litologias com interpretações genéticas distintas, o que, por consequência, levou à separação dessas em variadas unidades, todas com caráter ácido. Rochas básicas foram posteriormente incluídas nesta formação (Almeida et al. 2002, Wildner et al. 2002, Sommer et al. 2003, 2005) e, em decorrência disto, um caráter bimodal foi aventado para esse vulcanismo. A identificação recente, por meio de técnicas de sensoriamento remoto, de um corpo máfico com composição intermediária, intrusivo nas rochas ignimbríticas do Platô da Ramada (Pinheiro-Sommer et al. 2006), permitiu a reinterpretação do magmatismo e o questionamento quanto à sua bimodalidade.

Neste trabalho, foram apresentados e discutidos os aspectos geológicos, petrográficos e geoquímicos deste corpo máfico e sua relação com o magmatismo básico e ácido da Formação Acampamento Velho. Este corpo possui variação composicional de diorito a quartzo-diorito e neste trabalho é considerado como intrusão diorítica.

\section{CONTEXTO GEOLÓGICO}

Bacia do Camaquã e vulcanismo da Formação Acampamento Velho A Bacia do Camaquã tem sido interpretada como um lócus deposicional, no qual ocorreu a superposição de diversos tipos de bacias menores, cuja evolução é caracterizada pela alternância de intervalos em que dominaram eventos deposicionais, com o acúmulo de espessos pacotes

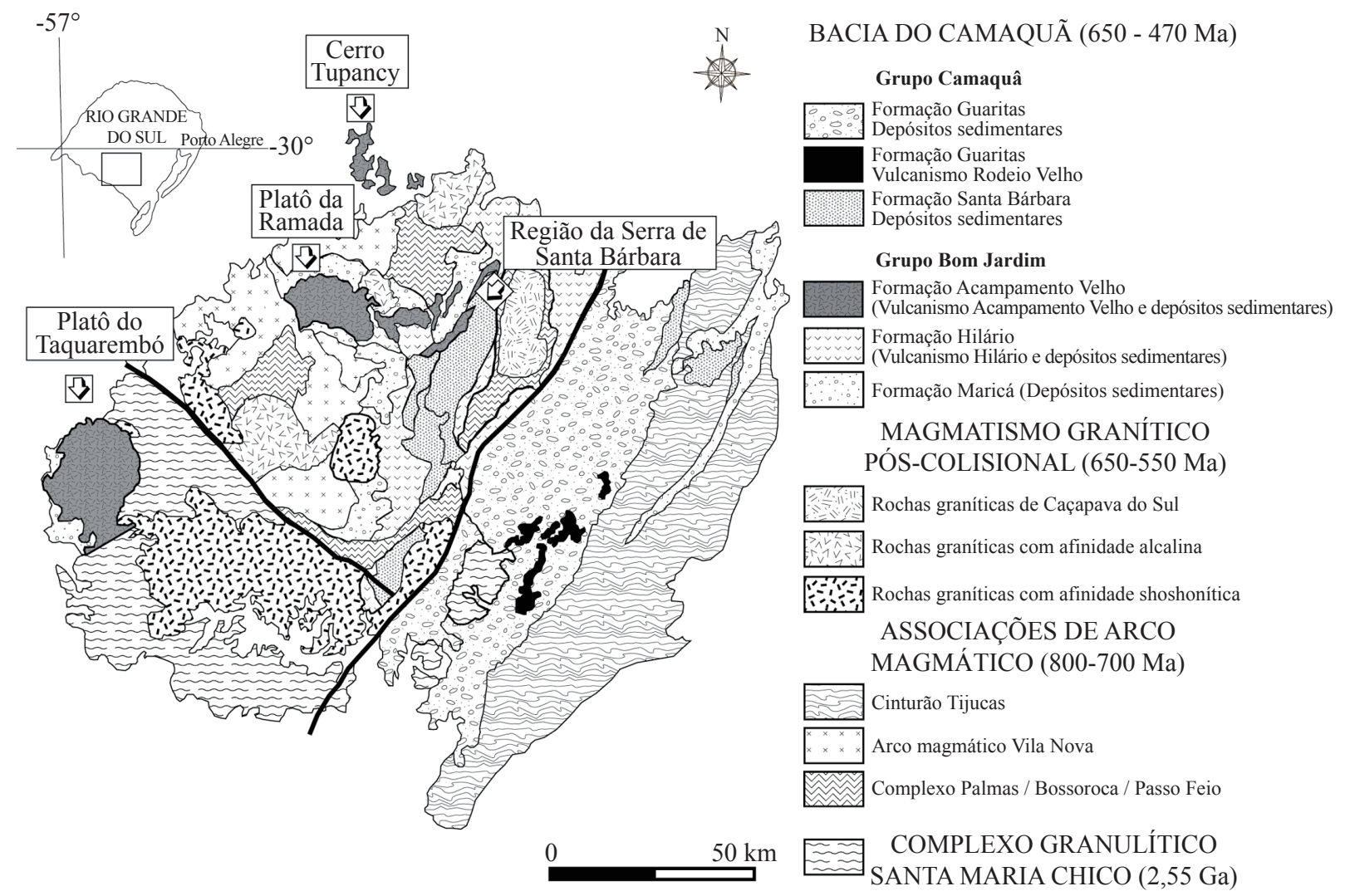

Figura 1 - Mapa com a localização do Platô da Ramada e com o contexto geológico regional. 
sedimentares e vulcano-sedimentares e intervalos dominantemente erosionais (Paim et al. 2000).

O vulcanismo Neoproterozoico-Ordoviciano desempenha papel importante dentro da evolução da Bacia do Camaquã, principalmente nas fases de preenchimento, nas quais os episódios vulcânicos dominaram, normalmente, na base das unidades de maior hierarquia. As características do magmatismo mostram uma evolução dos termos toleíticos e cálcico-alcalinos alto-K para shoshonítico, até alcalino sódico, sendo a contribuição crustal representada por granitoides peraluminosos (Sommer et al. 2006), como observado na Fig. 1.

Wildner et al. (2002) organizaram os episódios vulcânicos da Bacia do Camaquã em diferentes ciclos, estabelecidos em ambientes continentais, sob condições predominantemente subaéreas. Os ciclos vulcânicos foram individualizados em: vulcanismos Maricá, Hilário e Acampamento Velho, associados às formações homônimas; vulcanismo Rodeio Velho, vinculado ao Membro Rodeio Velho da Formação Guaritas (Fig. 1).

O vulcanismo da Formação Acampamento Velho reúne depósitos efusivos e piroclásticos de composição ácida, associados às lavas e aos diques de composição básica. A organização estratigráfica desta formação tem sido sugerida por diversos autores, como Wildner et al. (2002), Sommer et al. (1999, 2005) e Almeida et al. (2002). As melhores exposições estão localizadas no Platô da Ramada e no Cerro Tupanci, em Vila Nova do Sul, no Platô do Taquarembó (Dom Pedrito) e na Serra de Santa Bárbara (Caçapava do Sul).

As rochas ácidas do vulcanismo Acampamento Velho são dominantemente riolitos comendíticos, com ocorrência subordinada de rochas traquíticas de mesma afinidade. As rochas básicas reúnem um pequeno volume de lavas porfiríticas e diques geoquimicamente classificados como: hawaitos e mugearitos (Wildner et al. 2002, Almeida et al. 2002, Sommer et al. 2005).

Geologia do Platô da Ramada O Platô da Ramada (Fig. 2) é uma feição geomorfológica com espessura média em torno de $120 \mathrm{~m}$, distribuída em uma área de $24 \mathrm{~km}(\mathrm{E}-\mathrm{W})$ por $12 \mathrm{~km}(\mathrm{~N}-\mathrm{S})$, que agrupa episódios vulcânicos efusivos e piroclásticos. A unidade basal é composta por lavas intermediárias e conglomerados vulcanogênicos, vinculados à Formação Hilário, e sobreposto a esta unidade ocorrem rochas da Formação Acampamento Velho. O embasamento destas sequências vulcânicas é constituído principalmente por associações tonalíticas e básica-ultrabásicas metamorfisadas e por rochas sedimentares neoproterozoicas da Formação Maricá. O Platô é intrudido por granitoides alcalinos (Nardi \& Bonin, 1991) do Complexo Granítico Ramada e, parcialmente, recoberto por rochas sedimentares gonduânicas.

A Formação Acampamento Velho no Platô da Ramada é caracterizada pelo predomínio de ignimbritos, lavas e corpos hipabissais de composição ácida e, subordinadamente, por lavas básicas, podendo ser organizada estratigraficamente da seguinte maneira (Fig. 2):

- $\quad$ sequência explosiva, com depósitos de fluxo piroclástico, dispostos em camadas sub-horizontais, representados por ignimbritos ricos em líticos, tipo lenticulito e ricos em cristais. Diques básicos de 1 a $3 \mathrm{~m}$ de espessura e uma intrusão diorítica ocorrem cortando esta sequência piroclástica, principalmente na porção Sul do Platô.

- $\quad$ sequência efusiva, fluxo fissural de lavas riolíticas, apresentando desde termos coerentes, com diversos padrões texturais, maciços, foliados e até autoclásticos. Nas porções de topo desta sequência ocorrem, de maneira restrita, na porção NE do Platô, depósitos de lavas básicas.

\section{Caracterização geológica da intrusão diorítica}

A intrusão diorítica, localizada na porção Sul do Platô da Ramada (Fig. 2), foi identificada com o uso de técnicas de sensoriamento remoto, centradas principalmente no processamento digital de imagens ASTER (Pinheiro-Sommer et al. 2006).

A intrusão pode ser subdividida em duas porções, separadas por uma cunha ignimbrítica que se encontra encaixada em uma zona de falha com aproximadamente $600 \mathrm{~m}$ de largura. As rochas encaixantes são ignimbritos com alto grau de soldagem. A porção Oeste da intrusão tem em média $2 \mathrm{~km}$ de comprimento (E-W) e $600 \mathrm{~m}$ de largura (N-S) e a Leste possui dimensões de aproximadamente 3 (E-W) e 1,25 km (N-S).

O contato intrusivo entre o corpo diorítico e os ignimbritos é evidenciado pela presença de margens resfriadas caracterizadas pela gradação textural observada em direção ao contato, desde termos equigranulares finos até porfiríticos, algumas vezes com uma matriz afanítica. Constata-se ainda a presença de xenólitos, representados por fragmentos angulosos da rocha encaixante ignimbrítica.

O contato também ocorre em zonas de falha, nas quais uma tectônica rúptil posterior à intrusão 


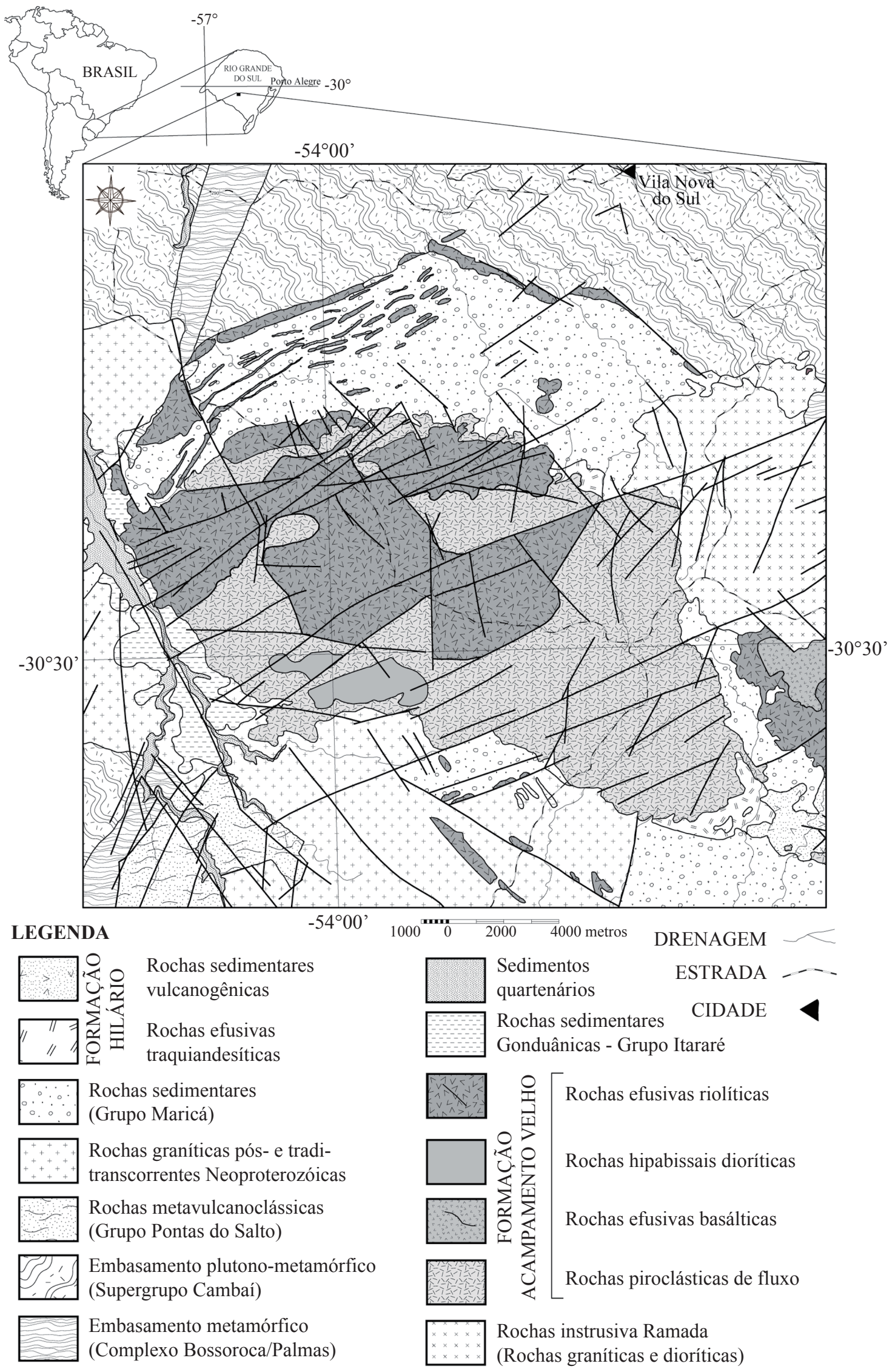

Figura 2 - Mapa geológico do Platô da Ramada (a partir de Sommer 2003 e Pinheiro-Sommer et al. 2006). 
afetou a área e é evidenciada pela presença de um forte fraturamento que atingiu tanto o corpo estudado quanto a sua encaixante, formando, em alguns casos, cataclasitos associados.

Macroscopicamente, a intrusão diorítica possui textura equigranular média à grossa e hipidiomórfica nas suas porções centrais, tornando-se porfirítica com fenocristais de plagioclásio (menos que $5 \%$ ) euédricos de até $5 \mathrm{~mm}$ e matriz fina à afanítica, próxima ao contato com a encaixante. A cor da rocha normalmente é acinzentada, porém alguns termos monzodioríticos possuem aspecto avermelhado. Nestes casos, observam-se fenocristais de plagioclásio envoltos por feldspato potássico, caracterizando a textura antirrapakivi.
PETROGRAFIA A estimativa visual realizada nos estudos petrográficos permitiu definir variações composicionais que, no sistema QAPF (Streckeisen 1978), correspondem desde dioritos até quartzo-monzonitos. Os minerais essenciais são plagioclásio, feldspato potássico e quartzo, sendo o anfibólio e a augita as fases máficas, acompanhadas de minerais acessórios como zircão, apatita e opacos. Clorita e calcita destacamse como minerais de alteração dos anfibólios.

O plagioclásio ocorre na matriz e como fenocristais (Fig. 3A). Os maiores fenocristais possuem até $6 \mathrm{~mm}$ e são euédricos, e a proporção matriz de fenocristais nos termos porfiríticos é 90:10. Alguns cristais possuem uma evidente zonação composicional,

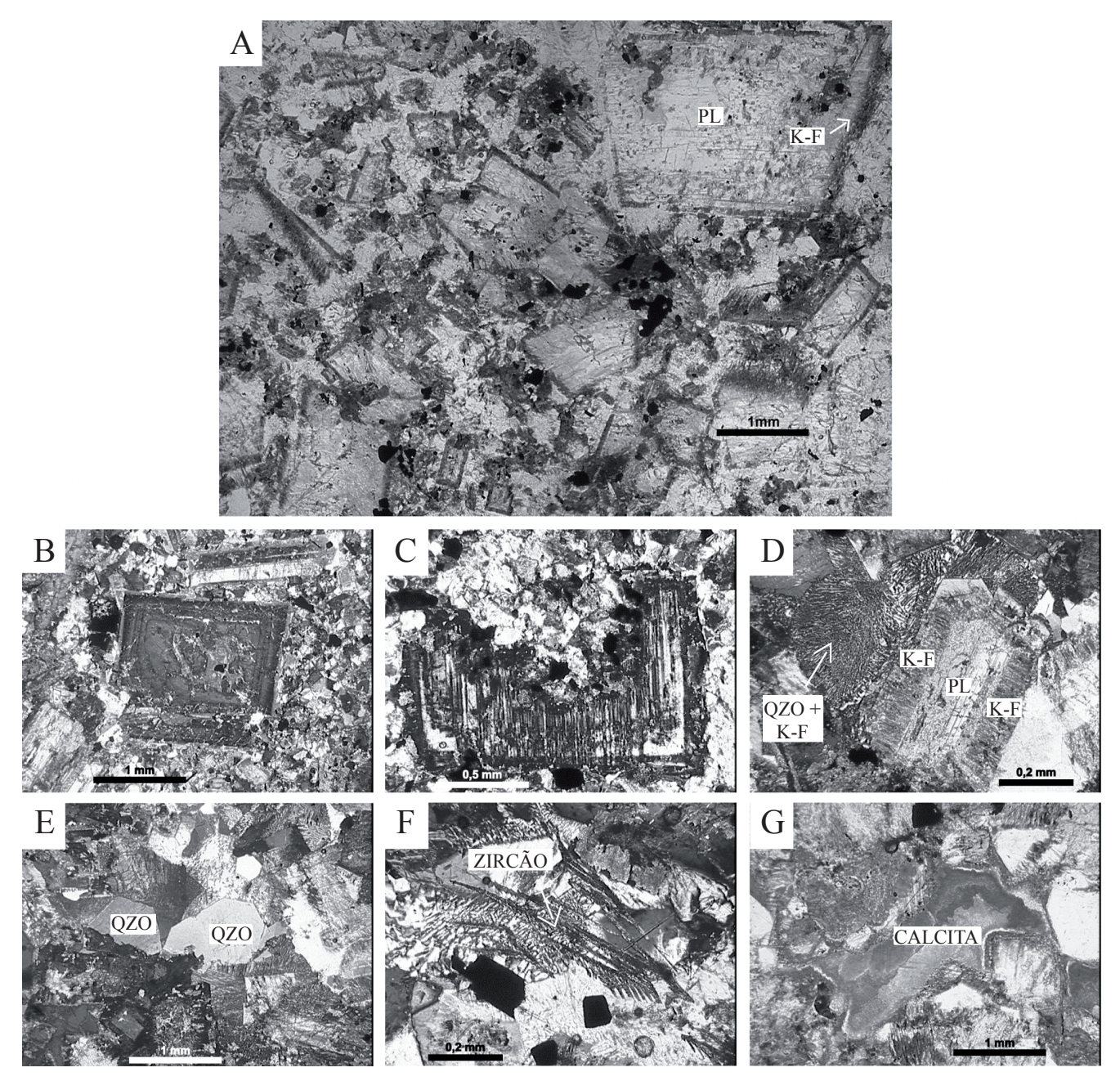

Figura $3-(A)$ diorito de petrotrama porfirítica, com fenocristais de plagioclásio (PL) envoltos por crescimento de feldspato potássico (K-F) (luz natural); (B) zonação em fenocristal de plagioclásio (luz polarizada); (C) reabsorção em fenocristal de plagioclásio (luz polarizada); (D) fenocristal de plagioclásio (centro) envolto por arranjo micrográfico - quartzo $(Q Z O)+$ feldspato potássico $(K-F)$ - (luz polarizada); (E) cristais subédricos de quartzo (QZO) (luz polarizada); (F) cristais de zircão com hábito acicular (luz polarizada); (G) calcita (CC) em interstícios granulares (luz natural). 
típica de corpos hipabissais (Fig. 3B). Nos termos dioríticos, os fenocristais apresentam bordas limpas, livres de inclusões e reabsorções. Em direção ao núcleo, esses fenocristais tornam-se completamente reabsorvidos (Fig. 3C). Alguns cristais estão parcialmente alterados para mica branca. Nos termos monzodioríticos e, principalmente, nos monzoníticos e quartzo-monzoníticos, é notável a ocorrência de bordas de feldspato potássico nos fenocristais de plagioclásio, caracterizando assim a textura antirrapakivi (Fig. 3D). Segundo Müller et al. (2008), a formação deste tipo de textura requer mudanças nas condições físico-químicas da cristalização (temperatura, pressão e composição do magma), as quais permitam ao sistema cristalizar feldspato potássico no lugar do plagioclásio. Geralmente o que ocorre é a entrada de um magma de diferente composição química, porém, outra causa pode ser atribuída a mudanças de pressão na câmara magmática.

O feldspato potássico está essencialmente restrito à cristalização tardia, anelando os grãos de plagioclásio (textura antirrapakivi) ou intercrescido com quartzo, formando textura micrográfica. Os crescimentos sobre os cristais de plagioclásio geralmente formam uma fina crosta de contatos nítidos e regulares, a qual, geralmente, não passa de $0,15 \mathrm{~mm}$ de espessura. Esta crosta possui uma coloração cinzaavermelhada, o que torna perfeita a distinção entre o limite do plagioclásio com o feldspato potássico. Ocorre crescimento de feldspato potássico tanto nos plagioclásios precoces quanto nos da matriz. O intercrescimento com quartzo formou massas anédricas que ocupam espaços intergranulares.

O quartzo, em geral, ocorre intercrescido com feldspato potássico, porém, em algumas laminas com menor quantidade de feldspato potássico, é comum a presença de cristais de quartzo anédricos a subédricos, com até $1 \mathrm{~mm}$ (Fig. 3E).

Prismas de anfibólio estão em geral alterados, como preenchimento de interstícios granulares, intensamente cloritizados. Ocasionalmente, ocorrem cristais subédricos, com até $2 \mathrm{~mm}$. Em alguns grãos, ainda é possível observar um fraco pleocroísmo verde-marrom e esporadicamente ocorre como exsolução da augita. Piroxênios ocorrem como raros cristais de augita, quase totalmente substituídos por anfibólio em menores temperaturas na cristalização.

A apatita em geral possui um hábito acicular com dimensões de até $2 \mathrm{~mm}$ e moda de $0,5 \mathrm{~mm}$, é comum em todas as lâminas observadas. Normalmente ocorrem associadas aos minerais tardios, principalmente inclusos em anfibólio. Os cristais de zircão geralmente possuem dimensões da ordem de $0,1 \mathrm{~mm}$, com hábito prismático subédrico a euédrico e, em alguns casos, lamelar à acicular, formando, nesses casos, feixes ou leques (Fig. 3F).

Minerais opacos são representados essencialmente por óxidos de ferro e possuem hábito subédrico a euédrico. Estão normalmente presentes junto aos minerais intersticiais.

A calcita ocorre como preenchimento de interstícios, resultado da cristalização tardia de líquidos ricos em carbonato de cálcio. Possui formas anédricas à subédricas de até $2 \mathrm{~mm}$. Uma fraca extinção ondulante é notável na maioria dos grãos (Fig. 3G). A clorita ocorre como produto de alteração dos anfibólios, preenchendo-se também os interstícios granulares.

\section{CARACTERIZAÇÃO GEOQUÍMICA DA IN- TRUSÃO DIORÍTICA}

Procedimentos analíticos Os estudos litoquímicos fundamentaram-se nas análises químicas de 12 amostras de rocha total, representativas da intrusão diorítica, cujos dados são apresentados na Tab. 1 . Os elementos maiores, traços e terras raras (ETR) foram analisados no Activation Laboratories Ltda., em Ontário, no Canadá, utilizando-se a técnica de espectrometria de emissão de plasma (Inductively Coupled Plasma-ICP) para os elementos maiores e espectrometria de emissão de plasma por espectrômetro de massa (Inductively Coupled Plasma Emission Mass Spectrometry - ICP-MS) para os elementos traço e ETR. No modelamento com elementos maiores, utilizou-se o programa computacional Petrograph (Petrelli et al. 2005), que se baseia no princípio da subtração de fases, semelhante ao clássico problema de subtração, idealizado em forma gráfica por Bowen (1928). O procedimento do programa é o de um típico balanço de massas, associado a um método de mínimos quadrados. Neste, a partir de líquido parental e final preestabelecidos, é calculada a proporção provável mais adequada de cada fase mineral conhecida a ser subtraída do líquido inicial, bem como a quantidade de fracionamento necessária para atingir a composição final do líquido. Para confirmar os resultados obtidos com o balanço de massa, foi feito o modelamento para elementos traços, utilizando-se o programa NEWPET, que tem como princípio a utilização da Lei de Rayleigh, baseada na seguinte equação: $\mathrm{C}_{\mathrm{L}}=\mathrm{C}_{0} \times \mathrm{F}^{(\mathrm{D}-1)}$, onde $\mathrm{C}_{\mathrm{L}}=$ concentração 
Tabela 1 - Composição química das rochas dioríticas do Platô da Ramada. Elementos maiores e menores em peso\%; traços e ETR em ppm.

\begin{tabular}{|c|c|c|c|c|c|c|c|c|c|c|c|c|}
\hline & JU24 & RM308 & JU13 & Pto25e & Pto24c & RM312 & RM314 & RM305 & JU23 & RM306 & RM311B & JU22 \\
\hline $\mathrm{SiO}_{2}$ & 56,91 & 58,84 & 58,97 & 59,18 & 59,29 & 59,44 & 59,72 & 60,18 & 60,46 & 60,76 & 60,82 & 63,01 \\
\hline $\mathrm{Al}_{2} \mathrm{O}_{3}$ & 14,35 & 13,97 & 14,32 & 13,94 & 13,5 & 14,6 & 14,26 & 14,35 & 14,55 & 14,26 & 14,25 & 13,66 \\
\hline $\mathrm{Fe}_{2} \mathrm{O}_{3}(\mathrm{t})$ & 8,96 & 7,22 & 7,48 & 7,58 & 7,33 & 7,77 & 7,5 & 7,63 & 7,56 & 7,02 & 7,24 & 6,97 \\
\hline $\mathrm{MnO}$ & 0,15 & 0,14 & 0,14 & 0,14 & 0,15 & 0,16 & 0,16 & 0,14 & 0,15 & 0,12 & 0,16 & 0,18 \\
\hline $\mathrm{MgO}$ & 1,45 & 1,3 & 1,53 & 1,32 & 1,5 & 1,5 & 1,04 & 1,8 & 1,05 & 1,48 & 1,35 & 0,96 \\
\hline $\mathrm{CaO}$ & 4,9 & 3,99 & 4,25 & 4,27 & 3,95 & 4,61 & 3,94 & 3,48 & 3,69 & 3,69 & 3,72 & 2,63 \\
\hline $\mathrm{Na}_{2} \mathrm{O}$ & 3,51 & 3,43 & 3,51 & 3,55 & 3,66 & 3,76 & 3,82 & 3,89 & 3,96 & 3,77 & 3,73 & 3,73 \\
\hline $\mathrm{K}_{2} \mathrm{O}$ & 3,31 & 3,9 & 3,54 & 4 & 3,59 & 3,55 & 4,04 & 3,52 & 4,23 & 3,59 & 3,91 & 4,49 \\
\hline $\mathrm{TiO}_{2}$ & 1,49 & 1,35 & 1,24 & 1,23 & 1,23 & 1,51 & 1,35 & 1,39 & 1,08 & 1,28 & 1,30 & 0,85 \\
\hline $\mathrm{P}_{2} \mathrm{O}_{5}$ & 0,59 & 0,5 & 0,47 & 0,46 & 0,45 & 0,58 & 0,52 & 0,53 & 0,41 & 0,48 & 0,48 & 0,27 \\
\hline LOI & 4,17 & 4,35 & 4,41 & 4,23 & 4,9 & 3,47 & 4,28 & 3,95 & 2,55 & 4,16 & 3,56 & 2,62 \\
\hline Total & 99,78 & 98,97 & 99,86 & 99,91 & 99,54 & 101 & 100,6 & 100,9 & 99,71 & 100,6 & 100,5 & 99,37 \\
\hline $\mathrm{Rb}$ & 39 & 61 & 51 & 56 & 55 & 46 & 64 & 57 & 48 & 57 & 63 & 52 \\
\hline $\mathrm{Sr}$ & 210 & 264 & 212 & 206 & 212 & 255 & 174 & 228 & 151 & 246 & 258 & 74 \\
\hline $\mathrm{Ba}$ & 1228 & 1532 & 1324 & 1427 & 1470 & 1441 & 1536 & 1402 & 1563 & 1257 & 1806 & 1293 \\
\hline $\mathrm{Y}$ & 53 & 53,9 & 51 & 52 & 50 & 56,7 & 54,1 & 54,6 & 51 & 53 & 54,6 & 59 \\
\hline $\mathrm{Zr}$ & 619 & 724 & 599 & 755 & 663 & 731 & 760 & 723 & 921 & 710 & 734 & 1006 \\
\hline $\mathrm{Nb}$ & 20 & 17,6 & 18 & 21 & 19 & 17,7 & 17,7 & 17,4 & 19 & 17,1 & 17,2 & 19 \\
\hline $\mathrm{La}$ & 112 & 104 & 105 & 114 & 104 & 105 & 103 & 105 & 137 & 104 & 103 & 148 \\
\hline $\mathrm{Ce}$ & 226 & 208 & 208 & 228 & 198 & 211 & 208 & 212 & 268 & 210 & 209 & 275 \\
\hline $\operatorname{Pr}$ & 26,8 & 25,7 & 24,3 & 26,3 & 23,4 & 26,2 & 26 & 26,2 & 31,3 & 26 & 25,9 & 32,4 \\
\hline $\mathrm{Nd}$ & 99,9 & 82,5 & 91 & 96,3 & 87 & 84,9 & 83,6 & 84,7 & 115 & 83,1 & 83,4 & 119 \\
\hline $\mathrm{Sm}$ & 16 & 13,7 & 14,7 & 15,3 & 13,9 & 14,2 & 13,8 & 14,2 & 16,8 & 13,7 & 13,8 & 17,5 \\
\hline $\mathrm{Eu}$ & 4,53 & 3,71 & 3,96 & 3,97 & 3,94 & 3,93 & 3,73 & 3,95 & 4,59 & 3,64 & 3,67 & 4,3 \\
\hline Gd & 13,3 & 11,8 & 11,7 & 12,9 & 11,9 & 12,5 & 12,3 & 12,6 & 13,4 & 12,2 & 12,1 & 14,5 \\
\hline $\mathrm{Tb}$ & 1,9 & 1,8 & 1,6 & 1,8 & 1,8 & 1,9 & 1,85 & 1,89 & 1,8 & 1,83 & 1,84 & 2 \\
\hline Dy & 10 & 9,7 & 9,2 & 9,8 & 8,9 & 9,98 & 9,71 & 9,91 & 9,7 & 9,63 & 9,76 & 10 \\
\hline Ho & 1,8 & 1,81 & 1,7 & 1,8 & 1,7 & 1,9 & 1,78 & 1,85 & 1,8 & 1,78 & 1,82 & 1,9 \\
\hline $\mathrm{Er}$ & 5,4 & 5,25 & 4,9 & 5,4 & 4,8 & 5,44 & 5,22 & 5,44 & 5,3 & 5,31 & 5,36 & 5,8 \\
\hline $\mathrm{Tm}$ & 0,78 & 0,758 & 0,75 & 0,82 & 0,74 & 0,779 & 0,772 & 0,801 & 0,79 & 0,786 & 0,777 & 0,89 \\
\hline $\mathrm{Yb}$ & 4,9 & 4,81 & 4,8 & 5 & 4,7 & 4,94 & 4,83 & 4,96 & 5,1 & 4,87 & 4,92 & 5,8 \\
\hline $\mathrm{Lu}$ & 0,72 & 0,78 & 0,69 & 0,75 & 0,71 & 0,804 & 0,785 & 0,777 & 0,78 & 0,776 & 0,783 & 0,84 \\
\hline Hf & 12,3 & 13,7 & 11,8 & 14,5 & 12,9 & 13,8 & 14,1 & 14 & 16,5 & 13,9 & 14,1 & 18,2 \\
\hline $\mathrm{Ta}$ & 1 & 1,08 & 1 & 1,1 & 1 & 1,07 & 1,06 & 1,05 & 0,9 & 1,06 & 1,07 & 1,1 \\
\hline Th & 5,4 & 6,45 & 6,4 & 6,7 & 6,8 & 5,98 & 6,25 & 6,53 & 6,5 & 7,02 & 6,64 & 7,7 \\
\hline $\mathrm{U}$ & 0,9 & 1,29 & 1,2 & 1,1 & 1,2 & 1,21 & 1,33 & 1,32 & 1 & 1,44 & 1,35 & 1,2 \\
\hline $\mathrm{Cr}$ & $<20$ & $<20$ & $<20$ & $<20$ & $<20$ & $<20$ & $<20$ & $<20$ & $<20$ & $<20$ & $<20$ & $<20$ \\
\hline Co & 11 & 10 & 10 & 9 & 9 & 11 & 10 & 11 & 7 & 10 & 10 & 6 \\
\hline $\mathrm{Ni}$ & $<20$ & $<20$ & $<20$ & $<20$ & 20 & $<20$ & $<20$ & $<20$ & $<20$ & $<20$ & $<20$ & $<20$ \\
\hline $\mathrm{Cu}$ & 10 & 10 & $<10$ & 10 & 10 & 10 & 10 & 20 & 10 & 10 & 10 & 10 \\
\hline $\mathrm{Zn}$ & 100 & 110 & 80 & 90 & 90 & 120 & 110 & 120 & 80 & 100 & 110 & 80 \\
\hline $\mathrm{Ga}$ & 21 & 22 & 21 & 23 & 21 & 23 & 23 & 23 & 22 & 22 & 22 & 23 \\
\hline
\end{tabular}

do elemento estudado no líquido; $\mathrm{C}_{0}=$ concentração inicial; $\mathrm{F}=$ proporção de líquido remanescente $\mathrm{e}$ $\mathrm{D}=$ coeficiente de distribuição global (Tab. 1).

Na classificação no diagrama TAS para rochas plutônicas (Cox et al. 1979), as amostras ocupam o campo dos sienodioritos próximo ao campo dos quartzo-dioritos (Fig. 4), formando um trend comum em sequências moderadamente alcalinas saturadas em sílica. Esta mesma afinidade é observada no diagrama $\mathrm{Nb}$ versus $\mathrm{Zr} / \mathrm{TiO}_{2} * 0,0001$ (Winchester \& Floyd 1977), no qual as amostras também ocupam o campo das rochas traquiandesíticas.

No diagrama de Peacock (1931), as amostras têm um caráter álcali-cálcico tendendo a alcalino, mostrado pela intersecção dos trends $\mathrm{SiO}_{2} \mathrm{x}$ $\left(\mathrm{Na}_{2} \mathrm{O}+\mathrm{K}_{2} \mathrm{O}\right)$ e $\mathrm{SiO}_{2} \times \mathrm{CaO}$ (Fig. 5). A distinção entre as séries alcalinas saturadas em sílica de afinidade sódica e potássica (shoshonítica), usando-se o critério 


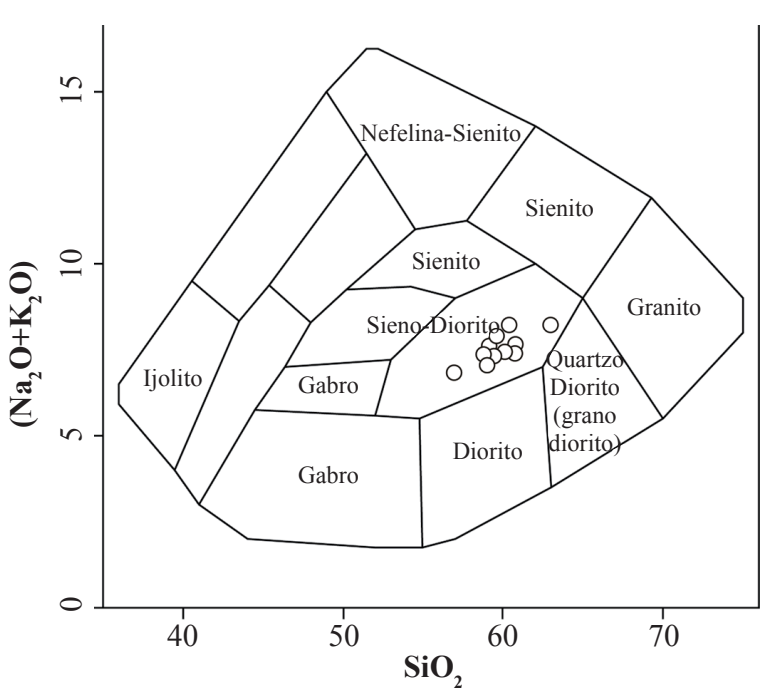

Figura 4 - Diagrama de classificação TAS para rochas plutônicas (Cox et al. 1979).

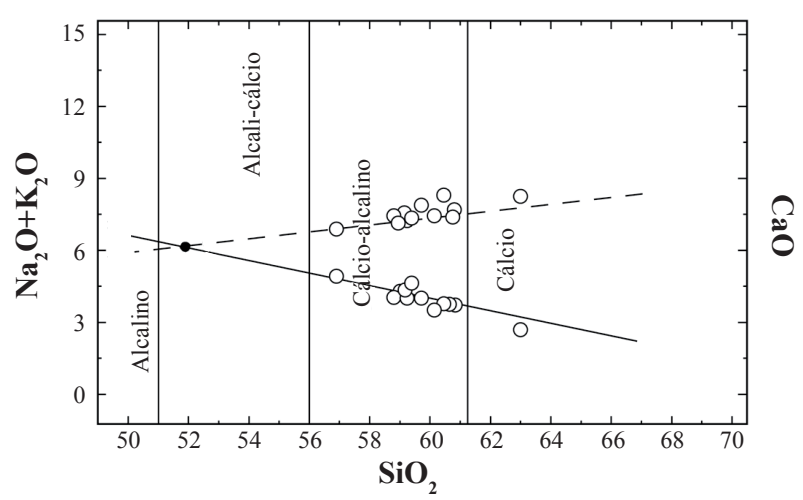

Figura 5 - Diagrama de Peacock (1931), mostrando o caráter álcali-cálcico tendendo a alcalino das rochas dioriticas. A linha pontilhada representa o trend $\mathrm{SiO}_{2} x$ Álcalis $\left(\mathrm{Na}_{2} \mathrm{O}+\mathrm{K}_{2} \mathrm{O}\right)$ e a linha cheia representa o trend $\mathrm{SiO}_{2} \times \mathrm{CaO}$.

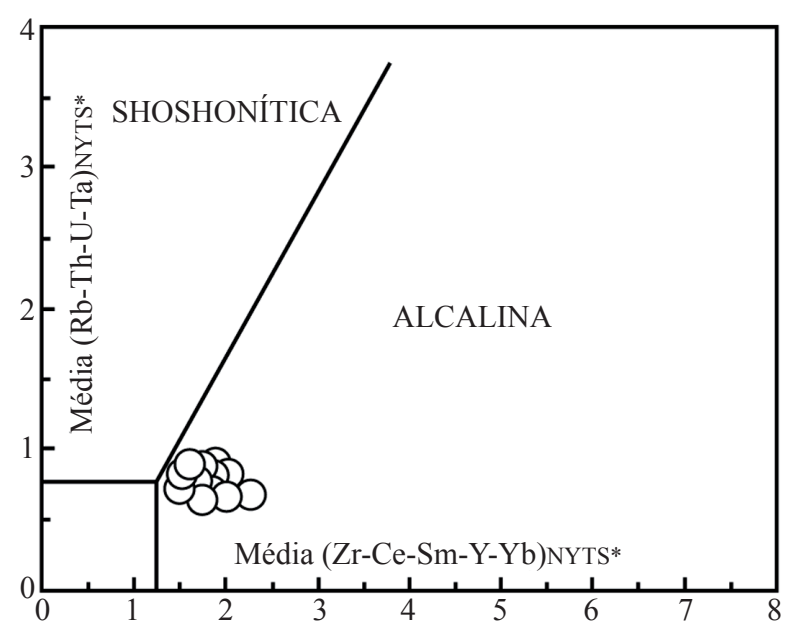

Figura 6-Diagrama sliding normalization (Liégeois et al. 1998). *NYTS: Normalization to the YenchichiTelabit series.
$\mathrm{Na}_{2} \mathrm{O}-2>\mathrm{K}_{2} \mathrm{O}$, fica prejudicada devido aos elevados teores de perda ao fogo das amostras estudadas (Lechler \& Desilets 1987). Como alternativa, utilizou-se o diagrama sliding normalization (Liégeois et al. 1998), visto na Fig. 6, que utiliza a média dos teores de $\mathrm{Zr}-\mathrm{Ce}-\mathrm{Sm}-\mathrm{Y}-\mathrm{Yb}$ versus a de $\mathrm{Rb}-\mathrm{Th}-\mathrm{U}-\mathrm{Ta}$, ambas normalizadas pelo NYTS. Neste diagrama, as rochas dioríticas ocupam o campo da série alcalina, plotando próximo ao limite com o campo da série shoshonítica, conferindo a elas uma natureza moderadamente alcalina.

Nos diagramas binários do tipo Harker (Fig. 7), os teores de $\mathrm{SiO}_{2}$ variam de 56,91 a $63,01 \%$, predominando composições em torno de $59 \%$. Os elementos Ba (1.228 a 1.806 ppm), Rb (39 a 64 ppm), Zr (599 a 1006 ppm), Y (50 a 59 ppm) e o somatório de álcalis $\left(\mathrm{Na}_{2} \mathrm{O}+\mathrm{K}_{2} \mathrm{O}\right)$ mostram correlação positiva com a sílica, enquanto que os elementos $\mathrm{FeOt}, \mathrm{CaO}, \mathrm{MgO}$, $\mathrm{TiO}_{2}, \mathrm{P}_{2} \mathrm{O}_{5}, \mathrm{Sr}(74$ a $264 \mathrm{ppm})$ e $\mathrm{Nb}(17$ a $21 \mathrm{ppm})$

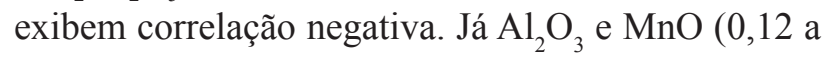
$0,18 \%$ ) apresentam-se aproximadamente constantes, independente da diferenciação.

Elevados valores de $\mathrm{FeOt}$ em relação a $\mathrm{MgO}$ e de álcalis caracterizam estas rochas como de afinidade alcalina sódica. $\mathrm{O}$ comportamento do $\mathrm{P}_{2} \mathrm{O}_{5}$ sugere fracionamento de apatita e o do $\mathrm{Rb}$ e do $\mathrm{K}_{2} \mathrm{O}$ sugere menor participação de uma fase potássica na evolução magmática destas rochas. Considerações teóricas e dados experimentais indicam que altos teores de $\mathrm{Zr}$ em magmas ocorrem devido à maior solubilidade de $\mathrm{Zr}^{+4}$ em líquidos com razões maiores de $\mathrm{Na}$ e $\mathrm{K}$ sobre os polímeros formados por cátions de $\mathrm{Si}$ e $\mathrm{Al}$ (Dietrich 1968, Watson \& Harrison 1983). Logo, em rochas félsicas peralcalinas, com enriquecimento de $\mathrm{Zr}$, a cristalização de zircão é tardia.

As rochas dioríticas quando normalizadas pelo padrão MORB (Pearce 1983) apresentam enriquecimento dos elementos entre $\mathrm{K}$ e $\mathrm{Sm}$, sendo $\mathrm{Sr}$, Ti, Y e Yb próximo ou abaixo da unidade (Fig. 8a). White \& Schilling (1978) interpretam esse tipo de padrão geoquímico como relacionado à incompatibilidade dos elementos em relação ao manto therzolítico, sendo o enriquecimento nos conteúdos de $\mathrm{Ba}, \mathrm{Th}$, $\mathrm{Ta}$ e $\mathrm{Nb}$ comum em magmas alcalinos. A anomalia negativa de $\mathrm{Sr}$ apresenta uma tendência de crescer em direção aos termos mais evoluídos e sugere a cristalização fracionada de plagioclásio na evolução deste magmatismo.

Quando normalizadas pelo padrão OIB de Sun \& McDonough (1989), as amostras mostram 


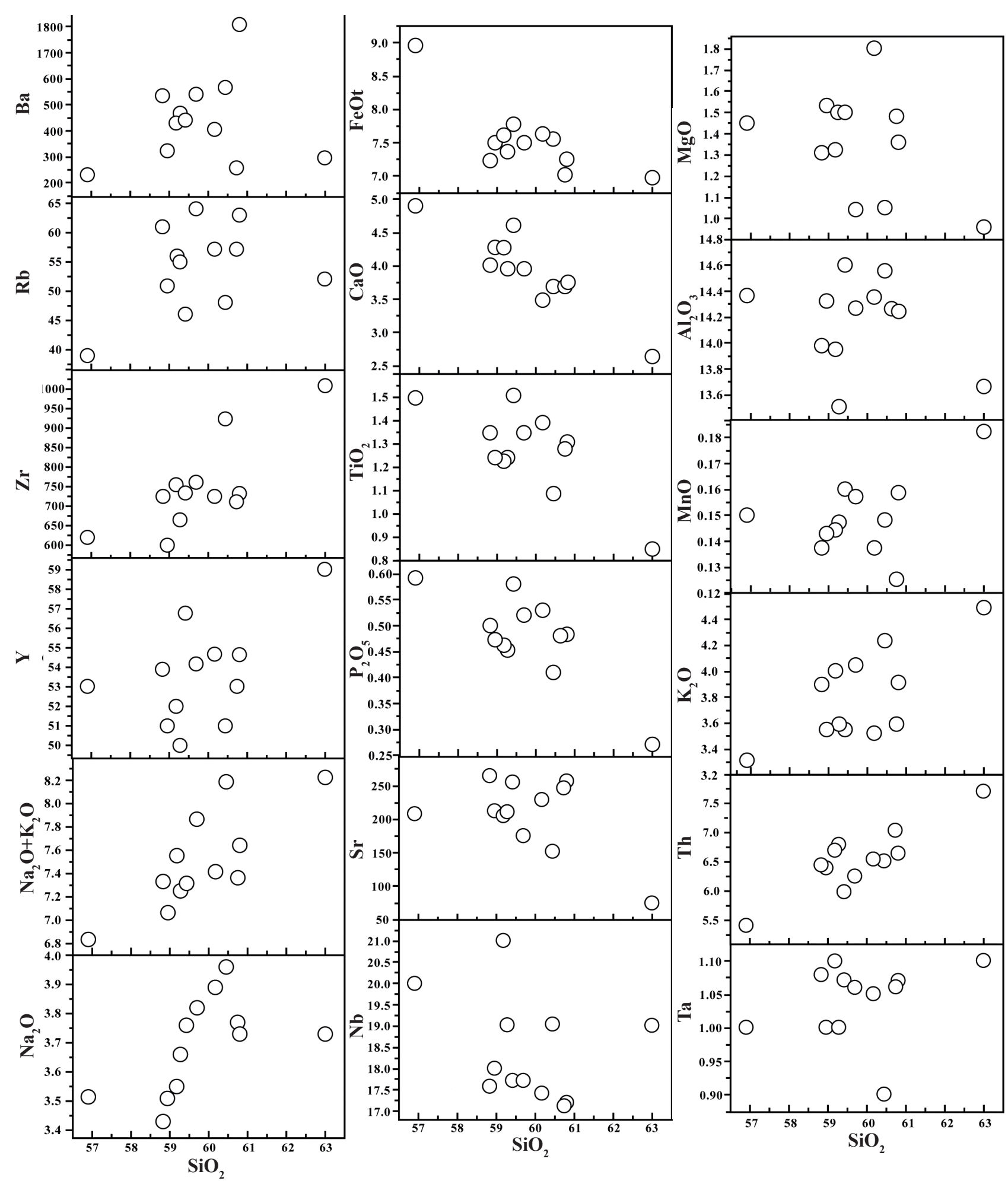

Figura 7 - Diagramas binários dos elementos maiores, menores e traços e somatório de álcalis da intrusão diorítica, utilizando $\mathrm{SiO}_{2}$ como índice de diferenciação.

enriquecimento em ETR, anomalias negativas de $\mathrm{Nb}$, Sr, Ti e HFSE e conteúdos elevados de Ba e K em relação a U e Th (Fig. 8B). Esse padrão geoquímico sugere que a fonte mantélica deste magmatismo foi modificada pela adição de elementos com baixo potencial iônico por fluidos aquosos. Alguns autores têm associado este padrão geoquímico à herança de subducção anterior (Saunders \& Tarney 1979).

Os padrões dos ETR, quando normalizados com o condrítico (Nakamura 1974), indicam conteúdos elevados destes elementos $\left(\Sigma_{\text {ETR }}=475-638\right) \mathrm{e}$ forte enriquecimento dos elementos terras raras leves 
- ETRL em relação aos elementos terras raras pesados - ETRP ( $\mathrm{La} / \mathrm{Yb}=14-18)$ (Fig. 9). Observa-se forte fracionamento em ETR leves $\left(\mathrm{La}_{\mathrm{N}} / \mathrm{Sm}_{\mathrm{N}}=4,3-5,2\right)$ e um leve em ETR pesados $\left(\mathrm{Eu}_{\mathrm{N}} / \mathrm{Yb}_{\mathrm{N}}=2,1-2,6\right)$. As anomalias de Eu são discretas, sendo que a razão $\mathrm{Eu} / \mathrm{Eu}^{*}{ }_{\mathrm{N}}$ fica em torno de 0,9 .

Os padrões observados para os ETR e o comportamento dos elementos litófilos de grande raio
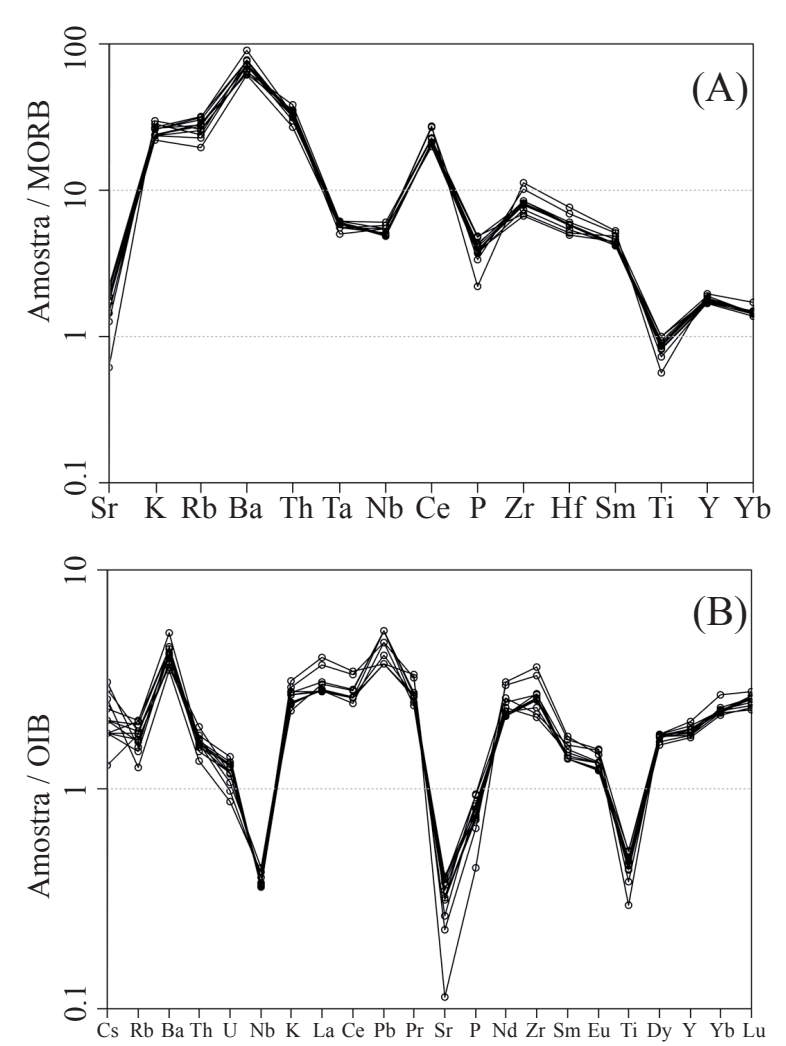

Figura 8-Diagramas multielementares mostrando o padrão dos elementos traços normalizados: (A) MORB (Pearce 1983) e (B) OIB (Sun \& McDonough 1989).

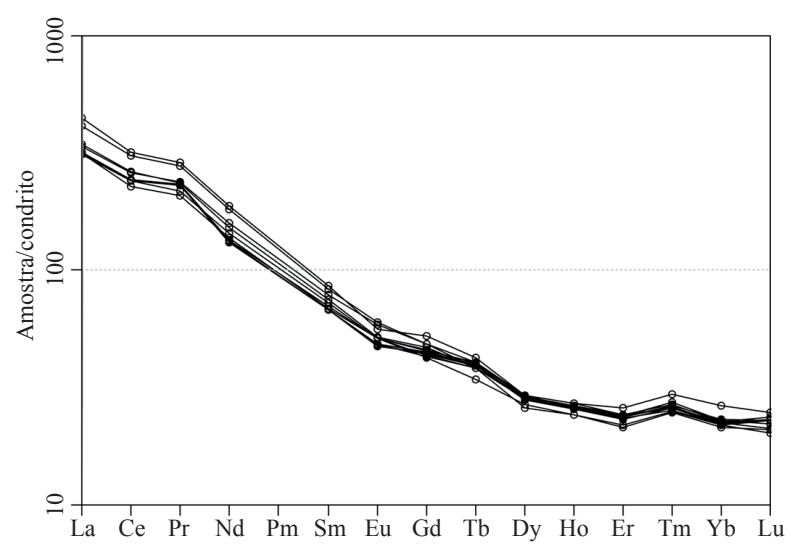

Figura 9 - Distribuição dos Elementos Terras Raras das rochas dioríticas normalizadas pelo padrão condrítico (Nakamura 1974). iônico (LILE) e dos elementos de elevado potencial iônico (HFSE), principalmente os altos teores de $\mathrm{Zr}$ e subordinadamente $\mathrm{Nb}, \mathrm{Y}$ e $\mathrm{Ga}$, são típicos de fontes mantélicas enriquecidas e são característicos de magmatismo de afinidade alcalina.

\section{RELAÇÕES PETROGENÉTICAS DA INTRU- SÃO DIORÍTICA COM O VULCANISMO AL- CALINO DA FORMAÇÃO ACAMPAMENTO \\ VELHO Na Formação Acampamento Velho,} predominam-se os termos ácidos, especialmente riolitos comendíticos e, em menor expressão, termos metaluminosos (Sommer et al. 2006, Wildner et al. 2002). O caráter peralcalino é expresso pelos elevados teores de $\mathrm{Zr}$ (Sommer et al. 2005). Os termos menos diferenciados são representados principalmente por basaltos transicionais e hawaitos, além de raros mugearitos.

Sommer et al. (2005) caracterizaram o vulcanismo bimodal da Formação Acampamento Velho da série alcalina sódica e saturada em sílica, separando, no Platô da Ramada, três grupos composicionais: basaltos-riolitos alto-Ti, basaltos-riolitos baixo$\mathrm{Ti}$ e riolitos alto- $\mathrm{Nb}$. Tais autores também sugerem que as rochas básicas baixo-Ti seriam caracterizadas por quantidades inferiores de $\mathrm{Ba}, \mathrm{Nb}, \mathrm{Y}, \mathrm{Zr}$ e ETR em relação aos basaltos alto-Ti e que as diferenças composicionais entre os magmas básicos alto e baixo $\mathrm{Ti}$ poderiam ser atribuídas aos diferentes graus de fusão de um manto litosférico.

Os riolitos baixo Ti são caracterizados por valores mais altos de $\mathrm{Rb}, \mathrm{Nb}$ e $\mathrm{Y}$ e conteúdos mais baixos de $\mathrm{Zr}$, Ce e $\mathrm{Sm}$ em relação aos riolitos alto Ti.

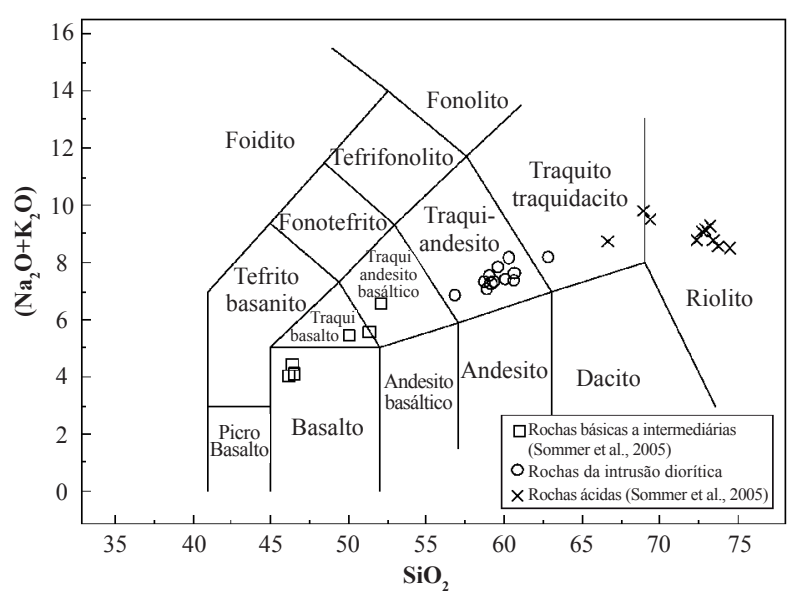

Figura 10 - Amostras do corpo diorítico e das rochas da Formação Acampamento Velho no Platô da Ramada plotados no diagrama TAS (Le Bas et al. 1986). 
Os riolitos alto- $\mathrm{Nb}$ apresentam conteúdos mais baixos de Fe e Ti e mais altos de $\mathrm{Nb}, \mathrm{Y}, \mathrm{Rb}$ e Ta, quando comparados com os outros dois grupos de riolitos. Os três grupos mostram conteúdos de Zr típicos de associações alcalinas levemente peralcalinas.

Os riolitos alto Ti possuem um enriquecimento em ETR, principalmente em ETRL, enquanto que os riolitos baixos Ti mostram padrão mais horizontalizado. Esses padrões são semelhantes aos encontrados nos basaltos, sugerindo, portanto, caráter comagmático, embora os processos e as relações entre os tipos alto e baixo Ti ainda não sejam completamente compreendidos.

Adicionando-se os dados geoquímicos das rochas dioríticas com os das básicas e ácidas do Platô da Ramada, constata-se uma similaridade com o termo composicional básico-ácido alto Ti. No diagrama TAS (Le Bas et al. 1986), utilizado para a classificação química de rochas vulcânicas, observa-se que as rochas dioríticas ocupam o campo das traquiandesíticas e preenchem a posição intermediária na composição bimodal do magmatismo Acampamento Velho, evidenciando um trend magmático, que, de acordo com o trabalho de Lameyre \& Bowden (1982), é característico de séries moderadamente alcalinas sódicas saturadas em sílica (Fig. 10). Sendo assim, o magmatismo relacionado à Formação Acampamento Velho estende-se desde hawaitos e basaltos até riolitos comendíticos a metaluminosos. Este trend magmático também é destacado no diagrama $\mathrm{FeOt} / \mathrm{MgO}$ versus $\mathrm{SiO}_{2}$ (Fig. 11), no qual observa-se um crescimento desta razão com a diferenciação e os valores elevados para os termos intermediários e ácidos, normalmente característicos de séries alcalinas.

Nos diagramas de variação entre elementos maiores e traços (Fig. 12) versus $\mathrm{SiO}_{2}$, as tendências observadas indicam a cristalização fracionada como processo predominante na evolução do magmatismo da Formação Acampamento Velho no Platô da Ramada.

As correlações negativa de $\mathrm{Al}_{2} \mathrm{O}_{3}, \mathrm{FeOt}, \mathrm{MgO}$, $\mathrm{CaO}$ e $\mathrm{TiO}_{2}$ e positiva de álcalis em relação à sílica sugerem a cristalização do piroxênio e plagioclásio na etapa evolutiva inicial entre líquidos básicos e intermediários e a formação de feldspatos potássicos, na evolução final dos líquidos traquíticos e riolíticos. Este comportamento é coerente com os resultados obtidos com os elementos traços, em que se constatam correlações negativas de $\mathrm{Sr}$ e positivas

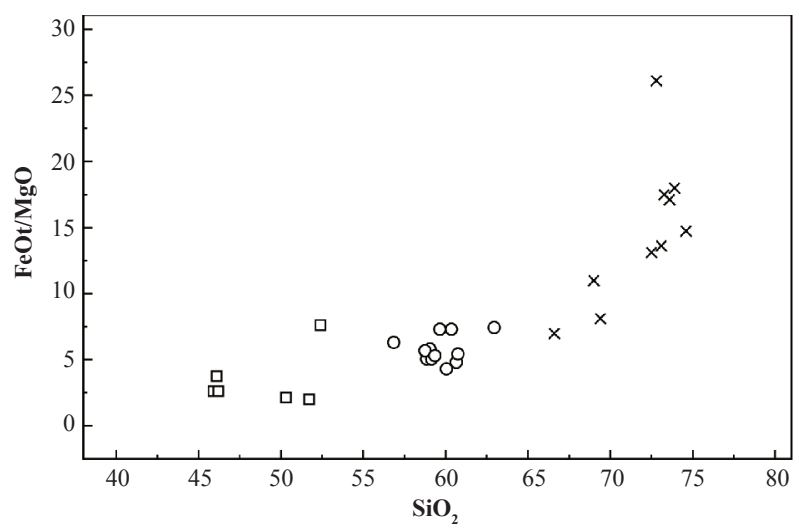

Figura 11 - Amostras do corpo dioritico e de rochas da Formação Acampamento Velho no diagrama $\mathrm{FeOt} / \mathrm{MgO} \times \mathrm{SiO}_{2}$.

de $\mathrm{Rb}, \mathrm{Y}, \mathrm{Zr}$, Nb e Th. O leve declínio nos teores de $\mathrm{Nb}$ nos termos intermediários pode estar refletindo a influência de contaminação crustal nesses líquidos (Wilson et al. 1995). O forte enriquecimento em Zr, a partir dos termos intermediários, pode ser justificado pela tendência de peralcalinidade do sistema (Leat et al. 1986). A queda nos conteúdos de Zr nos termos mais diferenciados $\left(>70 \% \mathrm{SiO}_{2}\right)$ reflete o fracionamento de zircão.

As razões entre elementos incompatíveis normalmente são constantes na evolução de líquidos comagmáticos. No caso das rochas dioríticas e básicas da Formação Acampamento Velho, o aumento na razão $\mathrm{Zr} / \mathrm{Nb}$ em direção às rochas intermediárias reflete a diminuição nos teores de $\mathrm{Nb}$, que pode ser reflexo da combinação de processos, envolvendo a contaminação crustal e o fracionamento de fases minerais, como titanita e ilmenita (Wilson et al. 1995), ao passo que, nos termos ácidos, a correlação negativa pode estar refletindo o fracionamento de zircão (Fig. 13). As elevadas razões $\mathrm{Zr} / \mathrm{Nb}(>10)$ podem estar relacionadas a fontes litosféricas modificadas pela subducção, com provável assimilação crustal, típicas de ambientes pós-colisionais ou de margens continentais ativas (Ewart 1979, Leat et al. 1986, MacDonald 1974, Sommer et al. 1999, 2005, 2006).

\section{Modelamento do magmatismo da Formação} Acampamento Velho no Platô da Ramada Entre os processos de diferenciação magmática, um dos mais efetivos é a cristalização fracionada. Em geral, a diferenciação entre líquidos magmáticos mais evoluídos (traquitos-riolitos) pode envolver, em menor escala, a assimilação crustal, conforme destacado por 


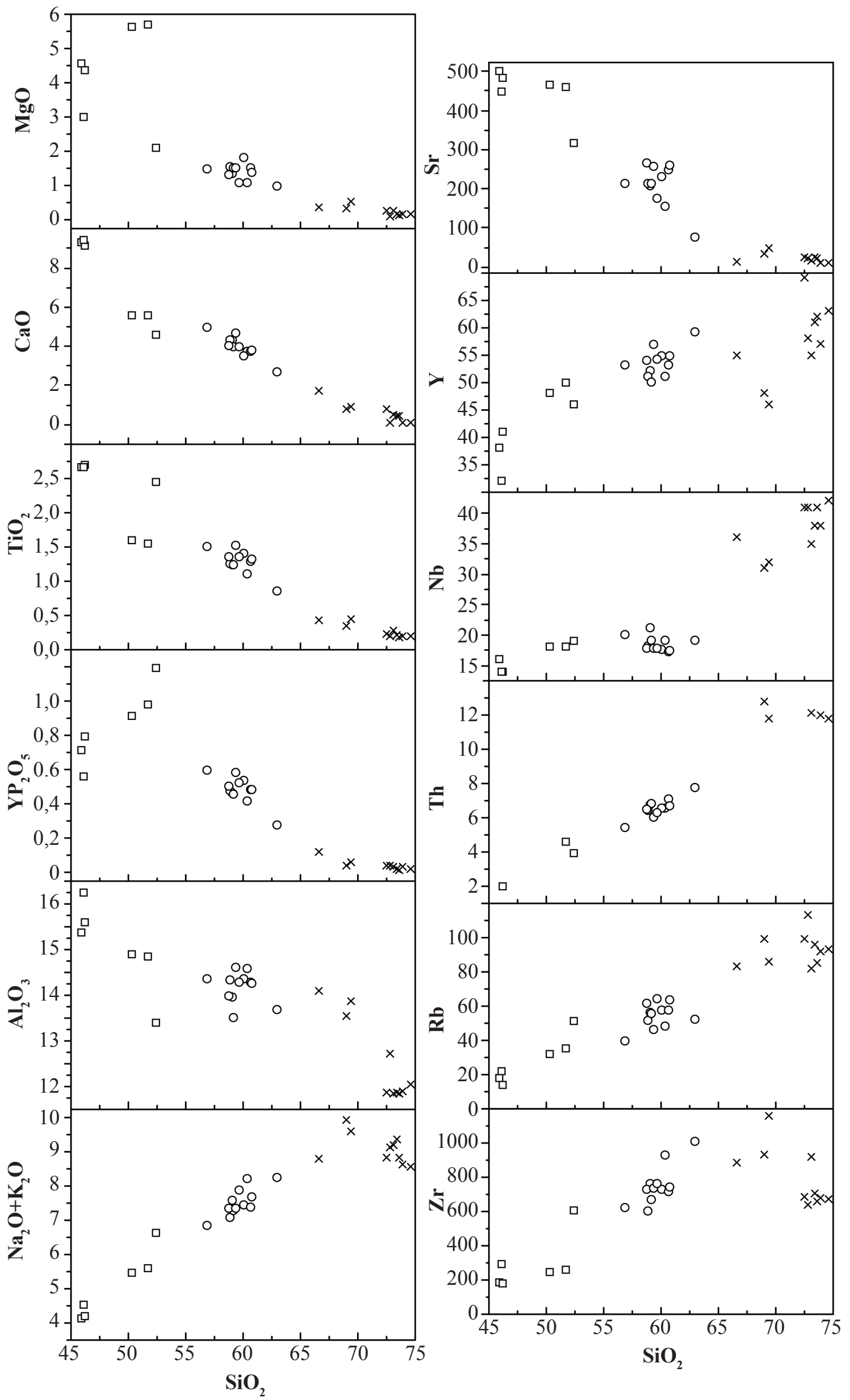

Figura 12 - Diagramas binários de elementos maiores e traços das rochas da Formação Acampamento Velho e do corpo diorítico no Platô da Ramada, utilizando $\mathrm{SiO}_{2}$ como índice de diferenciação. 
diversos autores: Turner et al. (1992), Wilson (1989), Ewart (1979), Chappell \& White (1992).

Visando o estudo da evolução magmática da Formação Acampamento Velho do Platô da Ramada, um modelamento geoquímico para cristalização fracionada foi realizado para as rochas básicas e intermediárias e para as intermediárias e ácidas.

Realizou-se um teste para o intervalo de 51,7 a $56,91 \%$ de $\mathrm{SiO}_{2}$, recalculado para base anidra, correspondendo a uma composição diorítica gerada a partir de um líquido básico. O líquido parental representa uma composição média entre as básicas com maiores teores de $\mathrm{MgO}$ da Formação Acampamento Velho (Sommer 2005), e o líquido final, uma média das composições dioríticas.

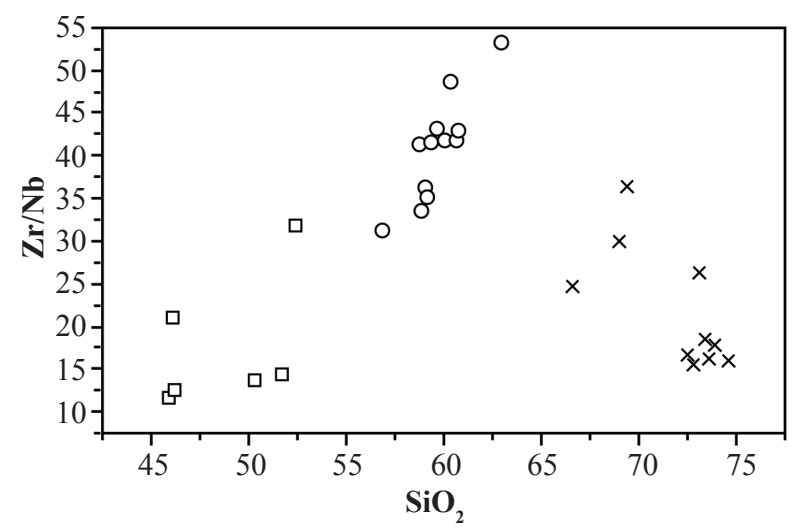

Figura 13 - Diagrama $\mathrm{Zr} / \mathrm{Nb}$ versus $\mathrm{SiO}_{2}$ para as amostras dioriticas e vulcânicas básicas e ácidas da Formação Acampamento Velho no Platô da Ramada.

Tabela 2 - Cálculo de balanço de massas para elementos maiores, envolvendo líquidos básicos e intermediários da Formação Acampamento Velho. Análises recalculadas para 100\%

\begin{tabular}{|c|c|c|c|c|c|c|c|c|c|c|c|}
\hline TESTE 1 & $\mathrm{~L}_{0}$ & $\mathrm{~L}_{1}$ & Cpx & $\mathrm{Ol}$ & Ti-mag & $\mathrm{Ab}$ & An & $\mathrm{F}$ & $\Delta_{\mathrm{o}}$ & $\Delta_{1}$ & Resíduos $\Delta_{\mathrm{o}}-\Delta_{\mathrm{i}}$ \\
\hline $\mathrm{SiO}_{2}$ & 53,83 & 59,89 & 51,97 & 37,48 & 0,00 & 68,58 & 44,55 & 49,46 & 6,05 & 5,95 & 0,11 \\
\hline $\mathrm{TiO}_{2}$ & 1,61 & 1,57 & 1,02 & 0,00 & 19,36 & 0,00 & 0,00 & 1,46 & $-0,04$ & 0,06 & $-0,10$ \\
\hline $\mathrm{Al}_{2} \mathrm{O}_{3}$ & 15,45 & 15,10 & 2,94 & 0,00 & 1,90 & 19,86 & 35,25 & 15,82 & $-0,35$ & $-0,41$ & 0,06 \\
\hline $\mathrm{FeOt}$ & 11,39 & 9,43 & 7,54 & 29,38 & 77,56 & 0,03 & 0,56 & 13,10 & $-1,96$ & $-2,09$ & 0,13 \\
\hline $\mathrm{MnO}$ & 0,18 & 0,16 & 0,11 & 0,00 & 0,38 & 0,00 & 0,00 & 0,04 & $-0,02$ & 0,07 & $-0,09$ \\
\hline $\mathrm{MgO}$ & 5,92 & 1,53 & 15,73 & 32,96 & 0,80 & 0,04 & 0,00 & 9,26 & $-4,40$ & $-4,41$ & 0,01 \\
\hline $\mathrm{CaO}$ & 5,79 & 5,16 & 20,24 & 0,18 & 0,00 & 0,00 & 18,79 & 6,39 & $-0,63$ & $-0,70$ & 0,07 \\
\hline $\mathrm{Na}_{2} \mathrm{O}$ & 4,11 & 3,69 & 0,42 & 0,00 & 0,00 & 11,19 & 0,80 & 4,37 & $-0,42$ & $-0,39$ & $-0,04$ \\
\hline $\mathrm{K}_{2} \mathrm{O}$ & 1,71 & 3,48 & 0,02 & 0,00 & 0,00 & 0,29 & 0,05 & 0,12 & 1,78 & 1,92 & $-0,14$ \\
\hline \multicolumn{9}{|c|}{ Soma dos quadrados dos Resíduos: } & \multicolumn{3}{|r|}{0,07} \\
\hline \multicolumn{3}{|c|}{ Fases fracionadas $(\%)$ : } & $-5,81$ & $-13,11$ & $-3,99$ & $-21,11$ & $-12,98$ & & & & \\
\hline \multicolumn{3}{|c|}{ Fases fracionadas $(100 \%)$ : } & 10,2 & 22,99 & 7,01 & 37,03 & 22,77 & & & & \\
\hline \multicolumn{3}{|c|}{ Fases adicionadas $(100 \%)$ : } & 0 & 0 & 0 & 0 & 0 & & & & \\
\hline \multicolumn{3}{|c|}{ Fases subtraídas $(100 \%):$} & 10,2 & 22,99 & 7,01 & 37,03 & 22,77 & & & & \\
\hline \multicolumn{3}{|c|}{ Total fracionado $(\%)$ : } & 57,01 & & & & & & & & \\
\hline
\end{tabular}

$\mathrm{L}_{0}$ : líquido inicial; $\mathrm{L}_{1}$ : líquido final; $\mathrm{F}$ : composição do fracionado; $\Delta_{0}$ : diferença observada entre magmas; $\Delta_{1}$ : diferença calculada entre magmas. As composições das fases minerais foram obtidas a partir do trabalho de Lima (1995).

Tabela 3 - Cálculo de balanço de massas para elementos maiores, envolvendo líquidos intermediários e traquiticos da Formação Acampamento Velho. Análises recalculadas para 100\%

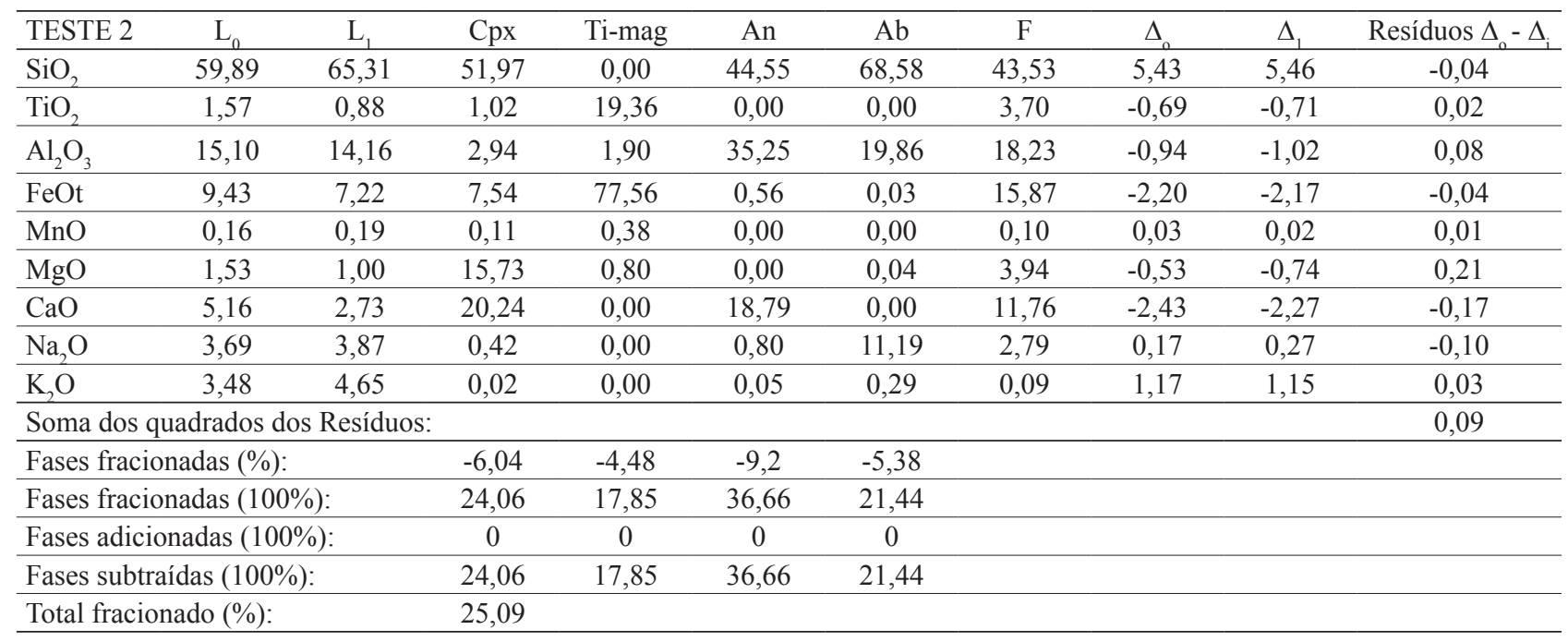

As composições das fases minerais foram obtidas a partir do trabalho de Lima (1995). 
Tabela 4 - Cálculo de balanço de massas para elementos maiores, envolvendo líquidos intermediários e ácidos da Formação Acampamento Velho. Análises recalculadas para 100\%

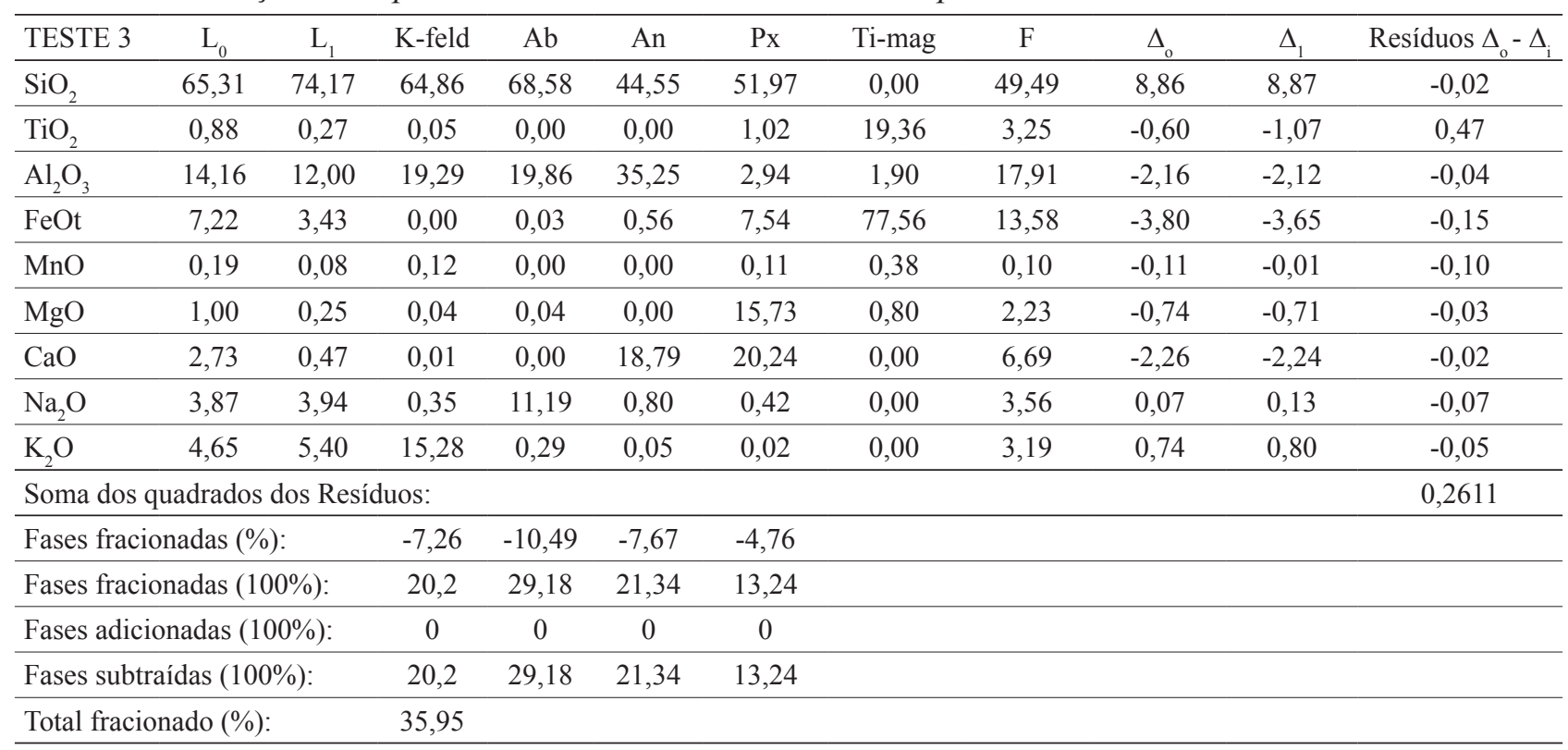

As composições das fases minerais foram obtidas a partir do trabalho de Lima (1995).

$\mathrm{L}_{0}$ : líquido inicial; $\mathrm{L}_{1}$ : líquido final; $\mathrm{F}$ : composição do fracionado; $\Delta_{\mathrm{o}}$ : diferença observada entre magmas; $\Delta_{\mathrm{i}}$ : diferença calculada entre magmas.

A escolha das fases minerais para o fracionamento fundamentou-se nos estudos petrográficos e as composições das fases minerais foram extraídas de Lima (1995), que descreveu rochas com mineralogia e afinidade geoquímica semelhantes às do corpo diorítico.

Os resultados obtidos são compatíveis com a hipótese de cristalização fracionada, sendo o volume de líquido final diorítico próximo à metade do inicial (Tab. 2). As percentagens de plagioclásio e das fases máficas sugerem uma composição do líquido primário do tipo olivina basalto (Yoder \& Tilley 1962), com caráter moderadamente alcalino saturado em sílica.

Em um segundo teste (Tab. 3), utilizou-se o intervalo de $56,91 \%$ de $\mathrm{SiO}_{2}$ (composição do líquido final do teste anterior) até $63,01 \%$ de $\mathrm{SiO}_{2}$, representando uma evolução de um líquido diorítico para uma composição traquítica. Os dados e resultados apresentados na Tab. 3 indicam baixo somatório do quadrado dos resíduos $(<1)$, com a extração de plagioclásio, clinopiroxênio e titanomagnetita do líquido parental diorítico. A extração de $25,12 \%$ na condição de fracionado, ou seja, de $1 / 4$ do volume inicial, seria suficiente para originar a composição traquítica.

Em seguida, utilizou-se o intervalo de 63,01\% de $\mathrm{SiO}_{2}$ (composição do líquido final do segundo teste) até $72,52 \%$ de $\mathrm{SiO}_{2}$, representando-se a evolução de um líquido traquítico para uma composição riolítica. Os dados e resultados apresentados na Tab. 4 indicam baixo somatório do quadrado dos resíduos $(<1)$, sugerindo que a extração de plagioclásio, clinopiroxênio, titanomagnetita e feldspato potássico no líquido parental traquítico poderia explicar a composição ácida escolhida como representativa da Formação Acampamento Velho, no Platô da Ramada. A extração de $38,85 \%$ na condição de fracionado seria suficiente para originar a composição ácida.

A partir dos dados de balanço de massa, realizou-se o modelamento com elementos traços, utilizando-se o software NEWPET, conforme metodologia descrita anteriormente. Os resultados são apresentados na Tab. 5. A diferença entre os dados calculados e observados deve-se, provavelmente, a uma variação entre os valores de coeficientes de partição $\left(\mathrm{K}_{\mathrm{d}}\right)$ utilizados pelo programa e os reais, obtidos por meio da análise química de cada fase mineral das rochas em questão.

Os dados obtidos aproximam-se daqueles apresentados por Sommer et al. (1999) no modelamento realizado para as rochas traquíticas e riolíticas da Formação Acampamento Velho no Platô do Taquarembó, com a utilização de elementos maiores e traços. Esses autores sugerem que a evolução do magmatismo ácido alcalino do Platô do Taquarembó estaria vinculada, principalmente, a processos de cristalização fracionada, associados, possivelmente, a mecanismos de assimilação crustal.

Como método alternativo para confrontar os dados obtidos no modelamento utilizando elementos 
Tabela 5 - Hipótese de cristalização fracionada testada através do modelamento de elementos traço. Os intervalos geoquímicos, a proporção de líquido fracionada, bem como das fases minerais utilizadas foram obtidos a partir do modelamento de elementos maiores (Tabelas 2, 3 e 4). Os campos preenchidos em cinza correspondem ao intervalo calculado para o fracionado

\begin{tabular}{|c|c|c|c|c|c|c|c|c|c|c|}
\hline \multirow{2}{*}{$\begin{array}{l}\text { Teste 1: } \\
\mathrm{L}_{0}: \mathrm{SiO}_{2}=\end{array}$} & \multicolumn{4}{|c|}{ líquidos básicos - intermediários } & \multirow[b]{2}{*}{ OLIV } & & & \multirow{2}{*}{\multicolumn{3}{|c|}{ Total Fracionado: $57 \%$}} \\
\hline & \multirow{2}{*}{$\begin{array}{l}51,70 \% \\
56,91 \% \\
\end{array}$} & \multicolumn{3}{|c|}{ Minerais fracionados: } & & & $23 \%$ & & & \\
\hline \multirow[t]{3}{*}{$\mathrm{L}_{1}: \mathrm{SiO}_{2}=$} & & & & & $\mathrm{CPX}$ & $10 \%$ & & & & \\
\hline & & & & & PLAG & $60 \%$ & & & & \\
\hline & & & & & MAG & $7 \%$ & & & & \\
\hline \multicolumn{11}{|c|}{ Concentração (ppm) } \\
\hline & $\mathrm{La}$ & $\mathrm{Nd}$ & $\mathrm{Yb}$ & $\mathrm{Rb}$ & $\mathrm{Sr}$ & $\mathrm{Ba}$ & $\mathrm{Y}$ & $\mathrm{Nb}$ & $\mathrm{Zr}$ & $\mathrm{Th}$ \\
\hline $\mathrm{L}_{0}$ & 58 & 52 & 4 & 35 & 458 & 933 & 50 & 18 & 259 & 4,6 \\
\hline $\mathrm{L}_{1}$ & 112 & 99,9 & 5 & 39 & 210 & 1228 & 53 & 20 & 619 & 5,4 \\
\hline \multicolumn{11}{|l|}{$\begin{array}{l}\text { Calculada } \\
\% \text { Frac }\end{array}$} \\
\hline 20 & 70,7 & 64,2 & 4,9 & 43,2 & 449,2 & 1130,9 & 61,8 & 22,3 & 321,9 & 5,7 \\
\hline 30 & 79,7 & 72,8 & 5,6 & 48,9 & 444,0 & 1268,8 & 70,2 & 25,4 & 366,7 & 6,6 \\
\hline 40 & 91,4 & 84,1 & 6,5 & 56,6 & 438,1 & 1449,1 & 81,2 & 29,5 & 426,1 & 7,6 \\
\hline 50 & 107,5 & 99,9 & 7,7 & 67,1 & 431,3 & 1695,6 & 96,6 & 35,1 & 508,9 & 9,2 \\
\hline 60 & 131,1 & 123,3 & 9,5 & 82,8 & 423,0 & 2055,2 & 119,4 & 43,6 & 632,6 & 11,4 \\
\hline Teste 2: & \multicolumn{4}{|c|}{ líquidos intermediários - traquíticos } & & & & & & \\
\hline $\mathrm{L}_{0}: \mathrm{SiO}_{2}=$ & $56,91 \%$ & \multicolumn{3}{|c|}{ Minerais fracionados: } & CPX & $24 \%$ & & \multicolumn{3}{|c|}{ Total fracionado: $25 \%$} \\
\hline \multirow[t]{2}{*}{$\mathrm{L}_{1}: \mathrm{SiO}_{2}=$} & $63,01 \%$ & & & & PLAG & $58 \%$ & & & & \\
\hline & & & & & MAG & $18 \%$ & & & & \\
\hline \multicolumn{11}{|c|}{ Concentração (ppm) } \\
\hline & $\mathrm{La}$ & $\mathrm{Nd}$ & $\mathrm{Yb}$ & $\mathrm{Rb}$ & $\mathrm{Sr}$ & $\mathrm{Ba}$ & $\mathrm{Y}$ & $\mathrm{Nb}$ & $\mathrm{Zr}$ & $\mathrm{Th}$ \\
\hline $\mathrm{L}_{0}$ & 112 & 99,9 & 5 & 39 & 210 & 1228 & 53 & 20 & 619 & 5,4 \\
\hline $\mathrm{L}_{1}$ & 148 & 119 & 5,8 & 52 & 74 & 1293 & 59 & 19 & 750 & 7,7 \\
\hline \multicolumn{11}{|l|}{$\begin{array}{l}\text { Calculada } \\
\% \text { Frac }\end{array}$} \\
\hline 20 & 129,3 & 110,5 & 5,5 & 48,4 & 144,5 & 1464,3 & 56,4 & 22,9 & 739,6 & 6,7 \\
\hline 30 & 140,8 & 117,4 & 5,9 & 55,1 & 115,5 & 1627,0 & 58,6 & 24,8 & 822,8 & 7,7 \\
\hline 40 & 155,5 & 125,9 & 6,3 & 64,0 & 89,2 & 1837,3 & 61,2 & 27,2 & 930,5 & 9,0 \\
\hline 50 & 174,8 & 136,8 & 6,8 & 76,3 & 65,7 & 2121,5 & 64,4 & 30,3 & 1076,2 & 10,8 \\
\hline 60 & 201,7 & 151,4 & 7,5 & 94,7 & 45,2 & 2529,8 & 68,6 & 34,6 & 1286,0 & 13,4 \\
\hline Teste 3: & \multicolumn{4}{|c|}{ líquidos traquíticos-riolíticos } & & & & & & \\
\hline $\mathrm{L}_{0}: \mathrm{SiO}_{2}=$ & $63,01 \%$ & \multicolumn{3}{|c|}{ Minerais fracionados: } & MAG & $14 \%$ & & \multicolumn{3}{|c|}{ Total fracionado: $36 \%$} \\
\hline \multirow[t]{4}{*}{$\mathrm{L}_{1}: \mathrm{SiO}_{2}=$} & $73,12 \%$ & & & & $\mathrm{~K}-\mathrm{F}$ & $23 \%$ & & & & \\
\hline & & & & & $\mathrm{CPX}$ & $13 \%$ & & & & \\
\hline & & & & & ZIRC & $2 \%$ & & & & \\
\hline & & & & & PLAG & $48 \%$ & & & & \\
\hline \multicolumn{11}{|c|}{ Concentração (ppm) } \\
\hline & $\mathrm{La}$ & $\mathrm{Nd}$ & $\mathrm{Yb}$ & $\mathrm{Rb}$ & $\mathrm{Sr}$ & $\mathrm{Ba}$ & $\mathrm{Y}$ & $\mathrm{Nb}$ & $\mathrm{Zr}$ & Th \\
\hline $\mathrm{L}_{0}$ & 148 & 119 & 5,8 & 52 & 74 & 1293 & 59 & 19 & 750 & 7,7 \\
\hline $\mathrm{L}_{1}$ & 173 & 131 & 5,9 & 82 & 15 & 300 & 55 & 35 & 914 & 12,10 \\
\hline $\begin{array}{l}\text { Calculada } \\
\% \text { Frac }\end{array}$ & & & & & & & & & & \\
\hline 20 & 171,6 & 135,5 & 1,7 & 63,5 & 35,1 & 1137,7 & 66,7 & 22,3 & 908,1 & 8,6 \\
\hline 30 & 187,5 & 146,5 & 0,9 & 71,5 & 22,5 & 1053,8 & 71,8 & 24,5 & 1018,2 & 9,7 \\
\hline 40 & 207,7 & 160,2 & 0,4 & 82,0 & 13,4 & 964,7 & 78,2 & 27,3 & 1161,9 & 11,2 \\
\hline 50 & 234,4 & 178,1 & 0,2 & 96,5 & 7,3 & 868,9 & 86,5 & 31,1 & 1358,5 & 13,3 \\
\hline
\end{tabular}



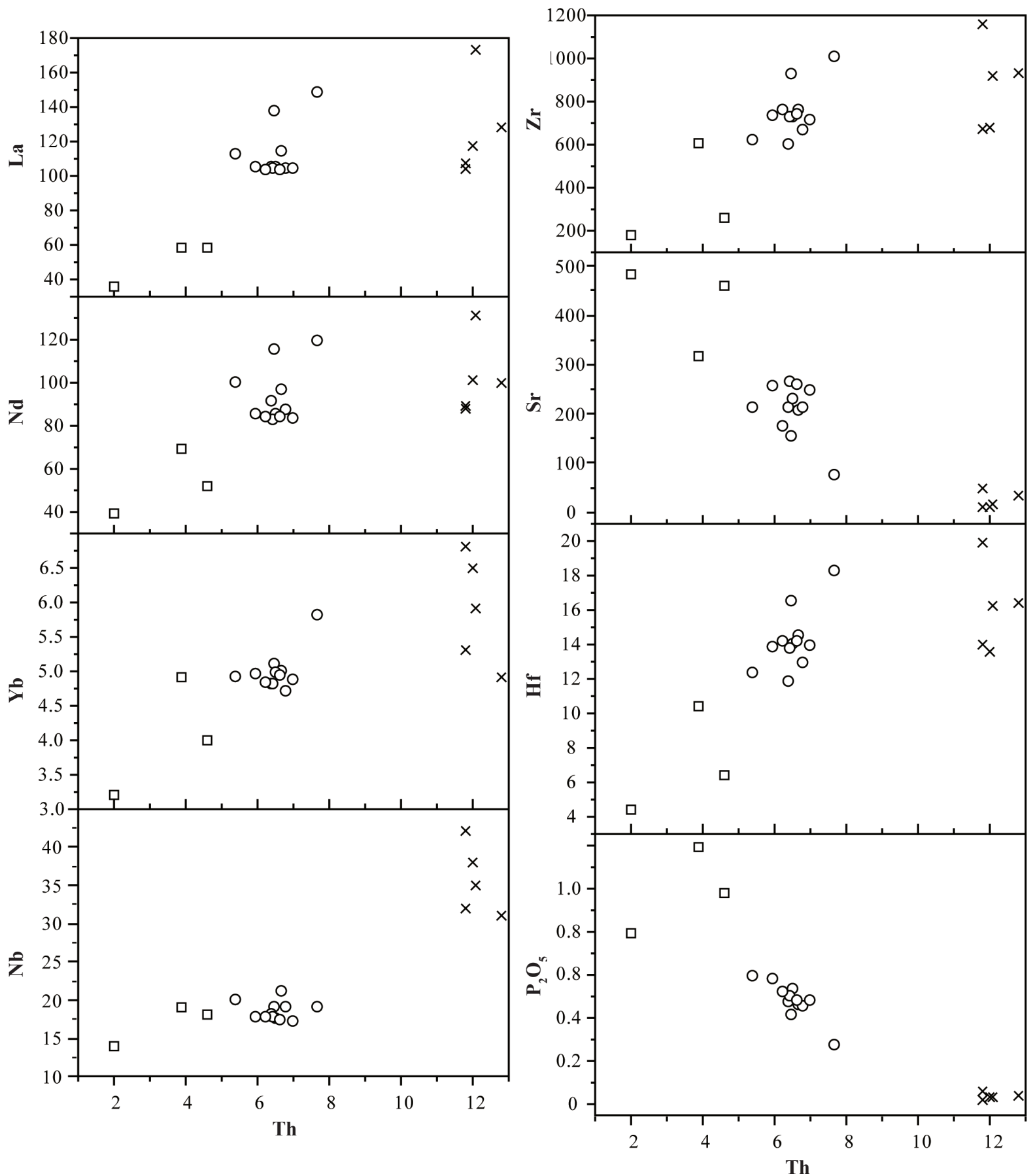

Figura 14 - Rochas básicas e ácidas da Formação Acampamento Velho e da intrusão diorítica do Platô da Ramada plotadas em diagramas de variação entre alguns elementos traços incompativeis e o Th como indice de diferenciação.

traços para testar a hipótese de cristalização fracionada em líquidos cogenéticos, alguns autores têm utilizado diagramas de variação com elementos traços altamente incompatíveis como índice de diferenciação (Allègre et al. 1977, Wilson et al. 1995). Este método é baseado na premissa de que em sistemas em que o coeficiente de distribuição global (D) é constante, o trend da cristalização fracionada tende a ser representado por uma reta, cuja declividade corresponderá à razão entre os Ds dos elementos traço em questão. Mesmo reconhecendo que em processos nos quais haja maior participação de assimilação crustal a situação seja mais complexa (Wyers \& Barton 1987), inflexões serão observadas nesta reta somente em casos em que a participação da assimilação seja mais acentuada (Defant \& Nielsen 1990).

A Fig. 14 mostra diagramas de variação entre alguns elementos traço em relação ao índice de diferenciação altamente incompatível representado pelo Th. De um modo geral, os trends observados na maioria dos elementos são compatíveis 
com mecanismos de cristalização fracionada, corroborando os dados apresentados nos modelamentos anteriores. Em geral, observa-se forte incompatibilidade da maioria dos elementos traço durante a evolução dos líquidos básico - intermediários, com exceção do $\mathrm{Sr}$ e do $\mathrm{P}_{2} \mathrm{O}_{5}$, os quais mostram acentuada compatibilidade, evidenciando o fracionamento de feldspatos e apatita ao longo dos estágios da diferenciação magmática.

CONSIDERAÇÕES FINAIS Petrograficamente, os litotipos estudados estão reunidos em um corpo hipabissal constituído por dioritos, quartzo-dioritos, monzodioritos e quartzo-monzodioritos no sistema QAPF (Streckeisen 1978), intrusivo nos depósitos ignimbríticos da Formação Acampamento Velho, na porção Sul do Platô da Ramada.

As rochas dioríticas são moderadamente alcalinas e saturadas em sílica e vinculadas à série sódica no diagrama sliding normalization (Liégeois et al. 1998), com caráter metaluminoso a peralcalino. Rochas com teores de $\mathrm{Zr}$ semelhantes aos dos dioritos ocorrem também na Suíte Intrusiva Saibro (QuartzoMonzonito Tuna) e foram descritas por Gastal et al. (1992), que as interpretaram como rochas de composição metaluminosa, com forte afinidade alcalina.

Os padrões observados para os ETR, LILs, HFSE e os altos teores de $\mathrm{Zr}$ e, subordinadamente, $\mathrm{Nb}, \mathrm{Y}$ e Ga são típicos de fontes mantélicas modificadas e são característicos de magmatismo de afinidade alcalina.

A geoquímica dos elementos maiores, traços e ETR das rochas dioríticas do Platô da Ramada permitiu correlacioná-las ao magmatismo da Formação Acampamento Velho nesta região, principalmente aos termos básico-ácidos alto Ti definidos por Sommer et al. (2005). As composições obtidas preenchem a lacuna entre os polos básico e ácido da Formação Acampamento Velho, porém não foram identificados andesitos nesta formação.

A origem e evolução de magmas alcalinos enriquecidos em sílica são normalmente complexas e diversos mecanismos têm sido propostos. Segundo Barth (1945), a assimilação de rochas crustais por um magma alcalino de origem mantélica poderia produzir um derivado sienítico que, por fracionamento, originaria uma composição riolítica. Outros autores admitem a fusão crustal (Collins et al. 1982, Whalen et al. 1987, Bailey 1974) para a geração de magmas alcalinos, no qual estes seriam derivados da fusão da crosta inferior sob a influência de voláteis de origem mantélica. Os riolitos peralcalinos, segundo outros autores (Philpotts 1976, Eby 1979), são gerados por imiscibilidade de líquidos em pequena escala, em magmas basálticos. Shaw et al. (1976) e Hildreth (1979) sugerem que a origem de variações químicas em alguns magmas riolíticos alcalinos estaria relacionada à difusão termogravitacional no estado líquido. A geração de líquidos riolíticos residuais produzidos pelo fracionamento de magmas alcalinos de origem mantélica tem sido proposta por Loiselle \& Wones (1979) e Collins et al. (1982). A fusão parcial de alta temperatura, diretamente a partir de uma fonte crustal empobrecida, do tipo I, também poderia formar magmas alcalinos (Collins et al. 1982, Whalen et al. 1987).

A hipótese de cristalização fracionada é defendida por Wilson (1989) e Turner et al. (1992), em combinação com um processo de contaminação crustal, como o maior responsável pela evolução de magmas alcalinos altamente diferenciados de basaltos transicionais ou moderadamente alcalinos. Essa hipótese tem sustentação também em dados de elementos traços e isótopos radiogênicos, obtidos em várias associações alcalinas vinculadas a um magmatismo típico de riftes continentais (Price et al. 1985). A evolução do magmatismo alcalino da Formação Acampamento Velho no Platô da Ramada pode ser explicada, principalmente, por processos de cristalização fracionada, que podem ter envolvido três etapas principais. Na primeira, a diferenciação de um magma básico $\left(\mathrm{SiO}_{2} \pm 52 \%\right)$, no qual $57 \%$ do líquido inicial cristalizaria olivina, piroxênio, titanomagnetita e plagioclásio, gerando um líquido traquiandesítico $\left(\mathrm{SiO}_{2} \pm 57 \%\right)$. Após esta fase, a diferenciação do magma intermediário obtido fracionaria aproximadamente $25 \%$ (piroxênio, titanomagnetita e plagioclásio), gerando um líquido final traquítico $\left(\mathrm{SiO}_{2} \pm 63 \%\right)$. Em uma última etapa, a diferenciação do magma traquítico residual geraria os riolíticos $\left(\mathrm{SiO}_{2} \pm 73 \%\right)$, com o fracionamento de feldspato potássico, plagioclásio, piroxênio e titanomagnetita.

Sugere-se que o processo de diferenciação magmática por cristalização fracionada possa explicar a variedade litológica observada no Platô da Ramada, relativa à evolução de parte do magmatismo alcalino sódico da Formação Acampamento Velho. No entanto, face ao grande volume de rochas riolíticas alta-sílica observado nesta unidade e, principalmente, à complexidade que envolve a geração e a evolução destes líquidos, é forte a possibilidade de que tenham ocorrido processos de cristalização fracionada associados 
possivelmente a mecanismos de assimilação crustal, como sugerido por Sommer et al. (1999).

A identificação e a caracterização de rochas intermediárias relacionadas à Formação Acampamento Velho, no Platô da Ramada, indicam, portanto, que o magmatismo evoluiu desde composições básicas até ácidas. Entretanto, a bimodalidade do vulcanismo permanece devido à ausência de lavas andesíticas, $o$ que pode ser atribuída a uma 'barreira de densidade' (Baker 1968, Bonnefoi et al. 1995), gerada pela diferenciação dos líquidos básicos para intermediários enriquecidos em $\mathrm{FeO}$, que, por esta razão, estacionariam nos níveis crustais rasos.
AGRADECIMENTOS Ao Conselho Nacional de Desenvolvimento Científico e Tecnológico $(\mathrm{CNPq})$ e à Fundação de Amparo à Pesquisa do Estado do Rio Grande do Sul (FAPERGS) pelos auxílios de pesquisa e bolsas de mestrado e produtividade de pesquisa (bolsa de mestrado processo $n^{\circ}$ 132465/2009-4) (CNPq: 470641/2008-8; 303584/2009-2; 470488/2010-7; 470505/2009-10 FAPERGS: 10/005940; PRONEX: 10/0045-6). Ao Programa de Pós-Graduação em Geociências (PPGGEO) e ao Instituto de Geociências da Universidade Federal do Rio Grande do Sul (IGEO-UFRGS) pela infraestrutura e logística.

\section{Referências}

Allègre C.J., Treuil M., Minster J.F., Minster B., Albarède F. 1977. Systematic use of trace element in igneous process. Contribution to Mineralogy and Petrology, 60:57-75.

Almeida D.P.M., Zerfass H., Basei M.A., Petry K., Gomes C.H. 2002. The Acampamento Velho Formation, a Lower Cambrian Bimodal Volcanic Package: Geochemical and Stratigraphic Studies from the Cerro do Bugio, Perau and Serra de Santa Bárbara (Caçapava do Sul, Rio Grande do Sul, RS - Brazil). Gondwana Research, 5(3):721-733.

Bailey D.K. 1974. Continental rifting and alkaline magmatism. In: Sorensen H. (Ed.). The alkaline rocks. Chichester: Wiley, p. 148-159.

Baker I. 1968. Intermediate oceanic volcanic rocks and the Daly Gap. Earth and Planetary Science Letters, 4:103106.

Barth T.F.H. 1945. Studies of the igneous rock complex of the Oslo region II. Systematic petrography of the plutonic rocks. Skrifter ardet Norske Videnskaps Akademi, Oslo Matematisk - Naturviden-skapelig klasse, 1-104.

Bonnefoi C.C., Provost A., Albarede F. 1995. The 'Daly gap' as a magmatic catastrophe. Nature, 378:270-272.

Bowen N.L. 1928. The evolution of Igneous Rocks. Princeton: Princeton University Press, 344 p.

Chappel B.W. \& White A.J.R. 1992. I- and S-type granites in the Lachan fold belt. Special Paper Geological Society of America, 272:1-26.

Collins W.J., Beams S.D., White J.R., Chappell B.W. 1982. Nature and origin of A-type granites with particular reference to southeastern Australia. Contribution to Mineralogy and Petrology, 80:189-200.

Cox K.G., Bell J.D., Pankhurst R.J. 1979. The interpretation of igneous rocks. London: Allen \& Unwin Publ, 450 p.

Defant M.J. \& Nielsen R.L. 1990. Interpretation of open system petrogenetic processes: Phase equilibria constraints on magma evolution. Geochimica et Cosmochimica Acta, 54:87-102.

Dietrich R.V. 1968. Behaviour of zirconium in certain artificial magmas under diverse P-T conditions. Lithos, $1: 20-29$.

Eby G.N. 1979. Mount Johnson, Quebec: An example of silicate liquid immiscibility? Geology, 7:491-494.

Ewart A. 1979. A review of the mineralogy and chemistry of Tertiary-Recent dacitic, latitic, rhyolitic and related salic volcanic rocks. In: Baker F. (Ed.). Trondhjemites, dacites and related rocks. The Hague: Elsevier, p. 113-121.

Gastal M.C.P., Schmitt R.S., Nardi L.V.S. 1992. Granitóides da parte centro-sudoeste do Escudo Sul-rio-grandense: Novos dados e discussão sobre a gênese e tipologia do magmatismo alcalino. Pesquisas, 19(2):174-182.

Hildreth W. 1979. The Bishop Tuff: evidence for the origin of compositional zonation in silic magma chambers. Geological Society of America Special Paper, 180:43-74.

Lameyre J. \& Bowden P. 1982. Plutonic Rock Type Series: Discrimination of various Granitoid Series and related Rocks. Journal of Volcanology and Geothermal Research, 14:169-186.

Leat P.T., Jackson S.E., Thorpe R.S., Stillman C.J. 1986. Geochemistry of bimodal basalt - subalkaline/ peralkaline rhyolite provinces within the Southern British Caledonides. Journal of Geological Society, 143:259-273.

Le Bas M.J., Le Maitre R.W., Streckeisen A., Zanettin B. 1986. A chemical classification of volcanic rocks based on the total alkali-silica diagram. Journal of Petrology, 27:745-750.

Lechler P.J. \& Desilets M.O. 1987. A review of the use of loss on ignition as a measurement of total volatiles in whole-rock analysis. Chemical Geology, 63:341-344.

Leinz V., Barbosa A.F., Teixeira E.A. 1941. Mapa geológico Caçapava - Lavras. Boletim da Divisão de Fomento da Produção Mineral. Secretaria da Agricultura, Indústria e Comércio do Rio Grande do Sul, 90:1-39. 
Liégeois J.P., Navez J., Hertogen J., Black R. 1998. Contrasting origin of post-collisional high-K calcalkaline and shoshonitic versus alkaline and peralkaline granitoids. The use of sliding normalizantion. Lithos, 45:1-28.

Lima E.F. 1995. Petrologia das rochas vulcânicas e hipabissais da associação shoshonítica de Lavras do Sul, RS. Tese de doutorado em Geociências, Instituto de Geociências, Universidade Federal do Rio Grande do Sul, 339 p.

Loiselle M.C. \& Wones D.R. 1979. Characteristics and origin of anorogenic granites. Geological Society of America Abstracts with Programs, 11:468.

MacDonald R. 1974. Nomenclature and Petrochemistry of the peralkaline oversaturated extrusive rocks. Bulletin of Volcanologique, 38:498-516.

Müller A., Seltmann R., Kober B., Eklund O., Jeffries T., Kronz A. 2008. Compositional zoning of rapakivi feldspars and coexisting quartz phenocrysts. The Canadian Mineralogist, 46:1417-1442.

Nakamura N. 1974. Determination of REE, Ba, Fe, Mg, $\mathrm{Na}$ and $\mathrm{K}$ in carbonaceous and ordinary chondrites. Geochimica et Cosmochimica Acta, 38:757-775.

Nardi L.V.S. \& Bonin B. 1991. Post-orogenic and nonorogenic alkaline granite associations: the Saibro intrusive suite, southern Brazil - a case study. Chemical Geology, 92:197-212.

Paim P.S.G., Chemale F. Jr., Lopes R.C. 2000. A Bacia do Camaquã. In: De Ros L.F. \& Holz M. (Ed.). Geologia do Rio Grande do Sul. Porto Alegre: CIGO/UFRGS, p. 231-374.

Peacock M.A. 1931. Classification of igneous rock series. Journal of Geology, 39:54-67.

Pearce J.A. 1983. Role of the sub-continental lithophere in magma genesis at active continental margins. In: Hawkesworth C.J. \& Norry M.J. (Ed). Continental basalts and mantle xenoliths. Cheshire, UK: Shiva Publ., p. 230-256.

Petrelli M., Poli G., Perugini D., Peccerillo A. 2005. Petrograph: a New Software to Visualize, Model, and Present Geochemical Data in Igneous Petrology, Geochemistry, Geophysics and Geosystems, 6: Q07011, DOI 10.1029/2005GC000932. Disponível em: http://accounts.unipg.it/ maurip/SOFTWARE. htm. Acessado em: 26/03/2012.

Philpotts A.R. 1976. Silicate liquid immicibility. Its probable extent and petrogenetic significance. American Journal of Science, 276:1147-1177.

Pinheiro-Sommer J.A., Lima E.F., Saldanha D.L., Sommer C.A., Pierosan R. 2006. O uso de imagens do sensor ASTER no mapeamento de unidades vulcanosedimentares do Platô da Ramada, Vila Nova do Sul, RS. Pesquisas em Geociências, 33:23-36.

Price R.C., Johnson R.W., Gray C.M., Frey F.A. 1985. Geochemistry of phonolites and trachytes from the summit region of Mt. Kenya. Contributions to Mineralogy and Petrology, 89:394-409.
Sauders A.D. \& Tarney J. 1979. The geochemistry of basalts from a back-arc spreading center in the East Scotia Sea. Geochimica et Cosmochimica Acta, 43:555-572.

Shaw H.R., Smith R.L., Hildreth W. 1976. Thermogravitational mechanisms for chemical variations in zoned magma chambers. Geological Society of America Abstracts with Programs, 8:1102.

Sommer C.A. 2003. O vulcanismo neoproteozóico do Platô da Ramada, região de Vila Nova do Sul, RS. Tese de doutorado em Geociências, Instituto de Geociências, Universidade Federal do Rio Grande do Sul, 194 p.

Sommer C.A., Lima E.F., Nardi L.V.S. 1999. Evolução do vulcanismo alcalino na porção sul do Platô do Taquarembó, Dom Pedrito - RS. Revista Brasileira de Geociências, 29(2):245-254.

Sommer C.A., Lima E.F., Nardi L.V.S., Liz J.D., Pierosan R. 2003. Depósitos de fluxo piroclástico primários: caracterização e estudo de um caso no vulcanismo ácido neoproterozóico do Escudo Sul-Rio-grandense. Pesquisas em Geociências, 30(1):3-26.

Sommer C.A., Lima E.F., Nardi L.V.S., Figueiredo A.M.G., Pierosan R. 2005. Potassic and Low- and High-Ti Mildly Alkaline Volcanism in the Neoproterozoic Ramada Plateau, Southernmost Brazil. Journal of South American Earth Sciences, 18(3):237-254.

Sommer C.A., Lima E.F., Nardi L.V.S., Liz J.D. 2005a. The Neoproterozic Mildly Alkaline Bimodal Volcanism in Southern Brazil: Geological and Geochemical Aspects. International Geology Review, 47(10):1090-1110.

Sommer C.A., Lima E.F., Nardi L.V.S., Liz J.D., Waichel B.L. 2006. The evolution of Neoproterozoic magmatism in southernmost Brazil: shoshonitic, high-K tholeiitic and silica-saturated, sodic alkaline volcanism in postcollisional basins. Anais da Academia Brasileira de Ciências, 78:573-589.

Sun S.S. \& McDonough W. F. 1989. Chemical and isotopic systematics of oceanic basalts: implications for mantle composition and processes. In: Saunders A. D. \& Norry M. J. (Eds.) Magmatism in Ocean Basins. Geological Society of London Special Publication, 42:313-345.

StreckeisenA. 1978. IUGS Subcommision on the Systematics of Igneous Rocks. Classification and Nomenclature of Volcanic Rocks, Lamprophyres, Carbonatites and Melilite Rocks. Recommendations and Suggestions. Neves Jahrbuch für Mineralogie, 143:1-14.

Turner S.P., Foden J.D., Morrison R.S. 1992. Derivation of some A-type magmas by fractionation of basaltic magma: An example from the Padthway Ridge, South Australia. Lithos, 28:151-179.

Watson E.B. \& Harrison T.M. 1983. Zircon saturation revisited: temperature and composition effects in a variety of crustal magma types. Earth and Planetary Science Letters, 64:295-304.

Whalen J.B., Currie K.L., Chappell B.W. 1987. A-type granites: geochemical characteristics, discrimination and petrogenesis. Contributions to Mineralogy and Petrology, 87:319-327. 
White W.M. \& Schilling J.G. 1978. The nature and origin of geochemical variations in Mid-Atlantic ridge basalts from the central North Atlantic. Geochimica et Cosmochimica Acta, 42:5101-1516.

Wildner W., Lima E.F., Nardi L.V.S., Sommer C.A. 2002. Volcanic cycles and setting in the Neoproterozoic III to Ordovician Camaquã Basin succession in southern Brazil: characteristics of post-collisional magmatism. Journal of Volcanology and Geothermal Research, 118:261-283.

Wilson M. 1989. Igneous Petrogenesis. Londres: Unwin Hyman, 466 p.

Wilson M., Rosenbaum J.M., Dunworth E.A. 1995. Melilitites: partial melts of the thermal boundary layer? Contributions to Mineralogy and Petrology, 119:181-196.
Winchester J.A. \& Floyd P.A. 1977. Geochemical discrimination of different magma series and their differentiation products using immobile elements. Chemical Geology, 20:325-343.

Wyers G.P. \& Barton M. 1987. Geochemistry of a transitional ne-trachybasalt-Q-trachyte lava series from Patmos (Dodecanesos), Greece. Contributions to Mineralogy and Petrology, 97:279-291.

Yoder H.S.Jr. \& Tilley C.E. 1962. Origin of basalt magmas: An experimental study of natural and synthetic rock systems. Journal of Petrology, 3:342-532.

Manuscrito ID 20510 Recebido em: 11/01/2011 Aprovado em: 07/03/2012 